\title{
ION MOBILITY AND GAS-PHASE COVALENT LABELING STUDY OF THE STRUCTURE AND REACTIVITY OF GASEOUS UBIQUITIN IONS ELECTROSPRAYED FROM AQUEOUS AND DENATURING SOLUTIONS
}

\author{
by
}

Veronica Vale Carvalho

\begin{abstract}
A Thesis
Submitted to the Faculty of Purdue University

In Partial Fulfillment of the Requirements for the degree of
\end{abstract}

Master of Science

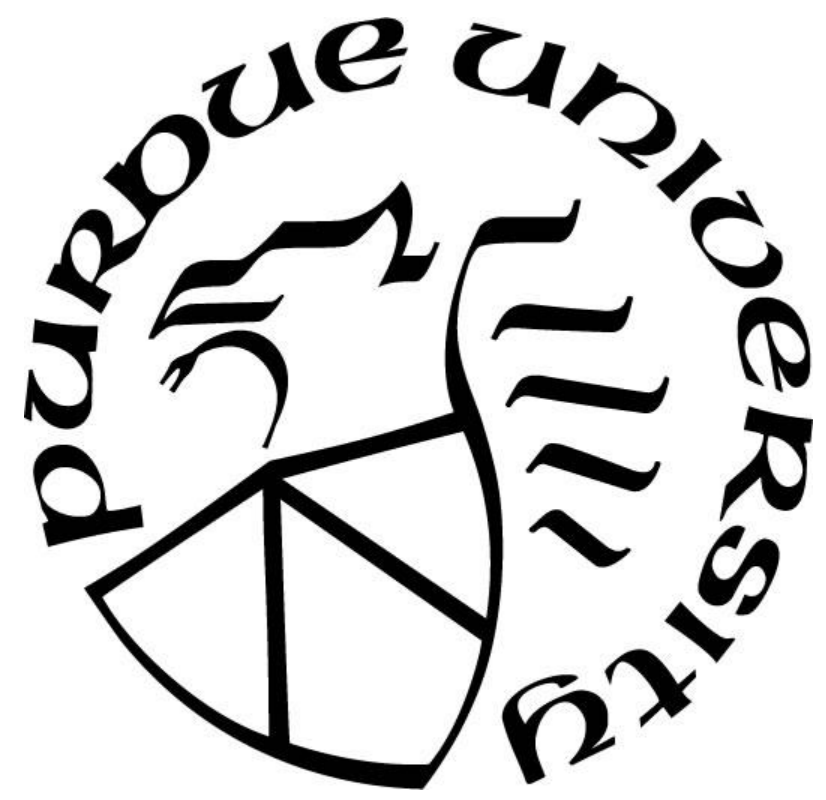

Department of Chemistry and Chemical Biology at IUPUI Indianapolis, Indiana

December 2021 


\title{
THE PURDUE UNIVERSITY GRADUATE SCHOOL STATEMENT OF COMMITTEE APPROVAL
}

\author{
Dr. Ian Webb \\ Chair \\ School of Science \\ Dr. Nicholas Manicke \\ School of Science \\ Dr. Sébastien Laulhé \\ School of Science
}

Approved by:

Dr. Eric Long 
Dedicated to my baby girl, Olivia. 


\section{ACKNOWLEDGMENTS}

I would like to gratefully acknowledge my advisor, Dr. Ian Webb, for his unconditional support for the obtention of my master's degree. Dr. Webb has always guided me through the good and rough moments with kindness and sympathy. Being a genius and deeply knowledgeable in his area did not get in his way of being a beautiful humble human with a giant heart. Thanks for all the lessons learned, whether life or academic lessons. I am so grateful for everything.

I want to thank the administrative staff of the chemistry department, Kitty, Lynn, and Bev. Thank you so much for all the help and patience. You guys never let me down and I really appreciate everything you have done for me.

Also, I would like to thank Dr. Nicholas Manicke for giving me the opportunity to start my journey at IUPUI and for all his help during this process.

I would like to thank Dr. Frederique Deiss for the talks, laughs and support during hard and good moments.

In special, I would like to thank my support community, my family and friends that are always by my side even being thousands of miles away.

Lastly, thanks to my husband Charles and my daughter Olivia. You are my everything. 


\section{TABLE OF CONTENTS}

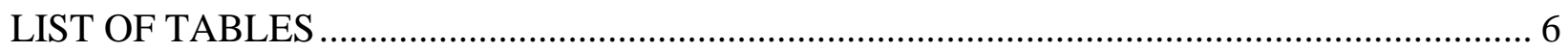



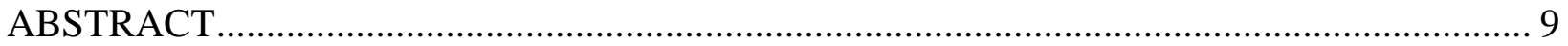

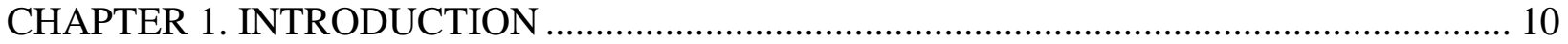

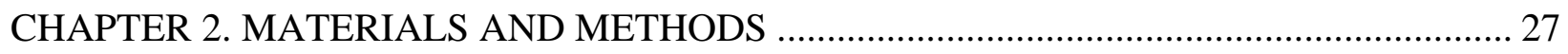

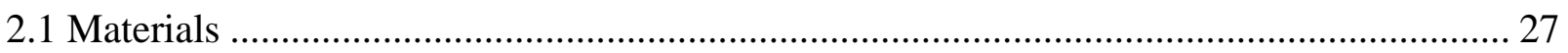

2.2 Sample Preparation ..................................................................................................... 27

2.3 Calibration of Travelling Wave-Ion Mobility Spectrometry Drift Times .......................... 27

2.4 Mass Spectrometry and Ion/Ion Reactions ..................................................................... 29

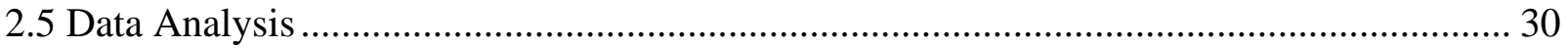

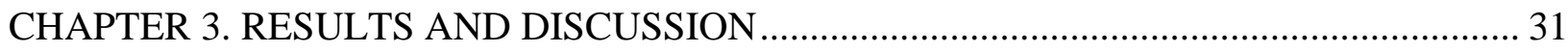

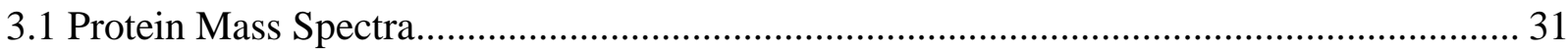

3.2 Gas-Phase Ubiquitin Conformations in the Trap Cells from Native and Denaturing

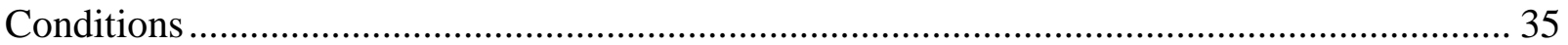

3.3 Characterization of Gaseous Ubiquitin Structures with Ion/Ion Reactions ........................ 40

3.3.1 Covalent Modification of Ubiquitin via Ion/Ion Reactions in the Gas Phase .............. 40

3.3.2 Comparison and Characterization of the Ubiquitin Ion Structures Obtained from

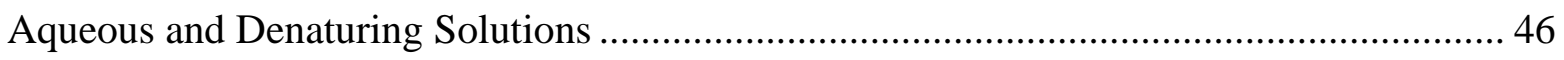

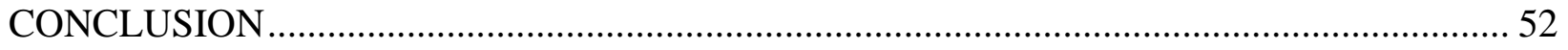



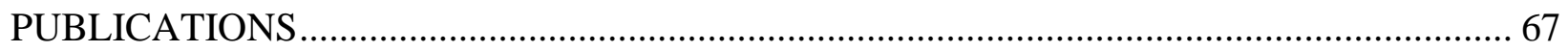




\section{LIST OF TABLES}

Table 1. List of advantages and disadvantages of analytical techniques used for biomolecule study. 11

Table 2. The instrument settings used in CCS measurements and ion/ion reactions for native and

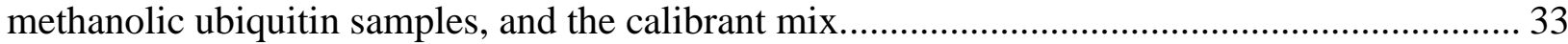

Table 3. CCS values, average, and standard deviation results calculated for the less extended conformations of ubiquitin ( $1^{\text {st }}$ peak) for both native and methanolic conditions..................... 36

Table 4. CCS values, average, and standard deviation results calculated for the less extended conformations of ubiquitin $\left(2^{\text {nd }}\right.$ peak) for both native and methanolic conditions. ..................... 36

Table 5. Center-of-mass energy ( $\left.\mathrm{E}_{\mathrm{COM}}\right)$ calculated for each charge state of ubiquitin during the

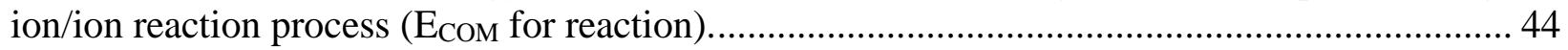

Table 6. Collision energy voltages applied to the transfer cell for each CID experiment........... 46 


\section{LIST OF FIGURES}

Figure 1. Basic components of a mass spectrometer...................................................... 12

Figure 2. Representation of an ESI source. Reprinted with permission from [16] Copyright 1996

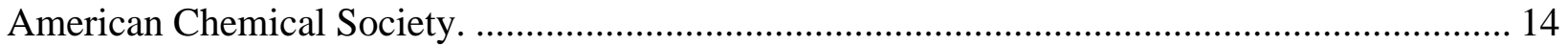

Figure 3. Schematic overview of the n-ESI ionization process. Reprinted with permission from [20].

Figure 4. Illustration of Synapt G2-Si High-Definition Mass Spectrometer developed by Waters Corporation. 16

Figure 5. Illustration of ion mobility technique TWIMS, where A) schematic of T-Wave IM cells (The IM T-Wave cell is not depicted to scale), and B) the progression of the travelling wave voltage pulse along the Stacked Ring Ion Guides - SRIG (left) and the 'surfing' of ions on the wave (right).

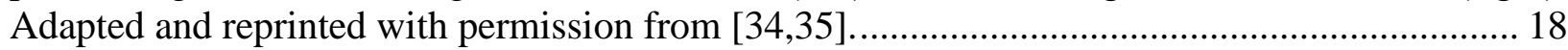

Figure 6. A stacked ring ion guide - SRIG. Reprinted with permission from [30]................... 19

Figure 7. Cartoon illustrating ion/ion reaction sequence. A) Anions (black) and B) cations (red) are introduced into the trap after mass selection, where the ion/ion reaction products (green) form. The bias of the trap can be raised with respect to the IM cell for collisional activation to drive off the leaving group from the covalent reaction (i.e., HOAt). C) Product ions are pulsed into the IM cell to separate products. The product ions are then fragmented by increasing collision energy into the transfer cell. Updated and reprinted with permission from [42] ....................................... 20

Figure 8. Covalent modification [ubiquitin $+5 \mathrm{H}]^{5+}$ with [sulfo-HOAt $\left.-\mathrm{H}\right]^{-}$generating the product [ubiquitin $\left.++4 \mathrm{H}+{ }^{*}\right]^{4+}$ via ion/ion reaction performed in the gas phase........................... 21

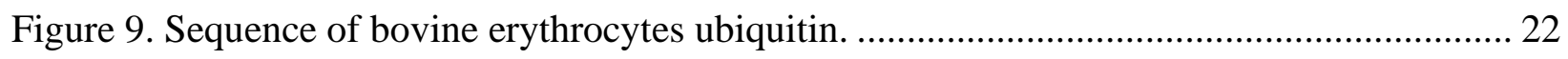

Figure 10. Conformations of the protein ubiquitin, where $\mathrm{N}$ represents the native-state, $\mathrm{A}$ is the $\mathrm{A}$ state, and $\mathrm{U}$ is the $\mathrm{U}$-state. Updated and reprinted with permission from [92]........................ 23

Figure 11. Representation of the basic differences between the 'top-down' and 'bottom-up' techniques. Reproduced with permission from [76] ............................................................ 25

Figure 12. Calibration curve obtained by plotting natural logarithm of the nitrogen CCS to charge ratios versus the calibrant ion drift times.

Figure 13. Mass spectra for ubiquitin electrosprayed from (top) native and (bottom) denaturing solution conditions used for CCS calibration and ion/ion reactions.

Figure 14. Intensity normalized arrival time distributions (ATDs) of ubiquitin $5^{+} \mathrm{A}$ ) and $6^{+} \mathrm{B}$ ) charge states sprayed from native (black trace) and denaturing (red trace) conditions. 37

Figure 15. CCS distributions for all charge states of electrosprayed ubiquitin ions from aqueous and denaturing solutions. The dashed lines denote the most elongated conformational state for both conditions. 39 
Figure 16. Covalent modification of [ubiquitin $+6 \mathrm{H}]^{6+}$ ionized from native conditions with [sulfoHOAt]- (A) Product ion spectrum of the ion/ion reaction between [ubiquitin $+6 \mathrm{H}]^{6+}$ and [sulfoHOAt $-\mathrm{H}]^{-}$prior to activation. refers to electrostatic attachment of the reagent and * refers to covalent modification. (B) ATD of the full scan (mass range of 100 to $500 \mathrm{~m} / \mathrm{z}$ ) corresponding to ion/ion reactions between [ubiquitin $+6 \mathrm{H}]^{6+}$ and $[\text { sulfo-HOAt }-\mathrm{H}]^{-}$revealing the mobility separation of covalently modified products generated with different extents of modification. (C) Mass spectrum resulting from CID of the ion/ion reaction product (corresponding to $72-83 \mathrm{~ms}$

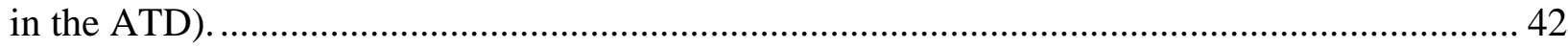

Figure 17. (A) Post-ion/ion reaction IM spectrum and mass spectra from zero (B), one (C), two (D), and three $(\mathbf{E})$ anion attachments. refers to electrostatic attachment of the reagent and $*$ refers to covalent modification. 45

Figure 18. A) MS/MS spectrum of Ubi $5^{+}$in aqueous conditions during ion/ion reactions. B) Ion fragment covalently modified $\mathrm{Y}_{24}{ }^{2+}+*(2909.4864 \mathrm{~m} / \mathrm{z})$ and C) Ion fragment covalently modified $\mathrm{B}_{32}{ }^{+}+*(3754.8975 \mathrm{~m} / \mathrm{z})$ 47

Figure 19. Sequence Ladder for Aqueous Ubiquitin in different charge states displaying the covalently modified fragmentation sites and the modified residues. 48

Figure 20. Sequence Ladder for Denatured Ubiquitin in different charge states displaying the covalently modified fragmentation sites and the modified residues. 48

Figure 21. X-ray structure of ubiquitin (1ubq). The blue residues (K29, R54) are labeled under native conditions and the red (K33, K48) and green residue (K27) are labeled only under denaturing conditions. The red residues are protonated under native conditions and the green residue is buried and participates in a salt bridge with D52 (black). K11 is black as it participates in a salt bridge but in not labeled under any conditions. The black line between K27 and D52 represents the salt bridge.... 49 


\begin{abstract}
Gas-phase ion/ion covalent modification was coupled to ion mobility/mass spectrometry analysis to directly correlate the structure of gaseous ubiquitin to its solution structures with selective covalent structural probes. Collision cross section (CCS) distributions were measured prior to ion/ion reactions to ensure the ubiquitin ions were not unfolded when they were introduced to the gas phase. Ubiquitin ions were electrosprayed from aqueous and methanolic solutions yielding a range of different charge states that were analyzed by ion mobility and time-of-flight mass spectrometry. Aqueous solutions stabilizing the native state of ubiquitin generated folded ubiquitin structures with CCS values consistent with the native state. Denaturing solutions favored several families of unfolded conformations for most of the charge states evaluated. Gas-phase covalent labeling via ion/ion reactions was followed by collision induced dissociation of the intact, labeled protein to determine which residues were labeled. Ubiquitin $5^{+}$and $6^{+}$electrosprayed from aqueous solutions were covalently modified preferentially at the lysine 29 and arginine 54 residues, indicating that elements of secondary structure as well as tertiary structure were maintained in the gas phase. On the other hand, most ubiquitin ions produced in denaturing conditions were labeled at various other lysine residues, likely due to the availability of additional sites following methanol and low $\mathrm{pH}$-induced unfolding. These data support the conservation of ubiquitin structural elements in the gas phase. The research presented here provides the basis for residue-specific characterization of biomolecules in the gas phase.
\end{abstract}




\section{CHAPTER 1. INTRODUCTION}

A protein's conformational states are the three-dimensional arrangement of constituent atoms, and play an imperative role in biological systems, being the center of many fundamental and applied research projects. The ability to determine the molecular structure of proteins with high resolution techniques is critical since the characterization of proteins is directly related to their biological activity performed in nearly all biological process that are present in a complex cellular regulatory network which includes regulated collaboration between numerous protein subunits in both time and space. Therefore, accessing the biological function of proteins is the key to understand biological process at the molecular level. [1, 2]

For many years preceding the genomics revolution, chemical or enzymatic methods were used to probe the primary structure of single, highly purified proteins. Described as one of the first studies involving protein structure and function is Sanger's sequencing work, which was developed based on his interest about providing insight into the mechanism of action of insulin. Sanger's work was based on applying fluorodinitrobenzene to break down proteins leading to endgroup analysis via partition chromatography probing an estimation of polypeptide chains' length and number. $[3,4]$

Aiming at the elucidation of amino acid sequences in proteins and peptides, Pehr Edman determined extended sequences of whole proteins or peptides by employing a two-part chemical reaction that involved the removal of one amino acid at a time from the $\mathrm{N}$-terminus. The removed amino acid that was then identified by reverse-phase high-performance liquid chromatography. [58]

Over the years, the increasing progress of analytical technologies applied to protein studies allowed the evolution from past assays that presented characteristics such as laborious, poorly sensitive and selective, created higher volumes of waste and consumables to become advanced analytical tools presenting higher efficiency, automation, accuracy, speed and cost-effectiveness, with the capability to provide superior information about the highly complex processes studied in the bioanalytical fields. [9] Some of the well-established techniques applied for protein characterization are surface plasmon resonance (SPR), Enzyme-linked immunoassay (ELISA), flow cytometry (FC), x-ray crystallography, nuclear magnetic resonance (NMR), and many others. 
A summary of specific characteristics of analytical techniques used for characterization of biomolecules is shown in Table 1. [10]

Table 1. List of advantages and disadvantages of analytical techniques used for biomolecule study.

\begin{tabular}{|c|c|c|}
\hline Analytical Technique & Advantages & Disadvantages \\
\hline $\begin{array}{l}\text { Surface Plasmon } \\
\text { Resonance (SPR) }\end{array}$ & $\begin{array}{l}\text { High sensitivity - capable of measuring } \\
\text { picomolar concentrations. }\end{array}$ & Expensive \\
\hline Gel Electrophoresis & $\begin{array}{l}\text { Inexpensive equipment } \\
\text { Easy handling }\end{array}$ & $\begin{array}{l}\text { Semi-quantitative technique. } \\
\text { Additional techniques are } \\
\text { required for precise } \\
\text { measurements. }\end{array}$ \\
\hline $\begin{array}{l}\text { Capillary } \\
\text { Electrophoresis (CE) }\end{array}$ & $\begin{array}{l}\text { Good resolution (especially when } \\
\text { compared to High Performance Liquid- } \\
\text { Chromatography - HPLC) }\end{array}$ & Expensive \\
\hline $\begin{array}{l}\text { X-Ray } \\
\text { Crystallography }\end{array}$ & $\begin{array}{l}\text { Three-dimensional structural analysis } \\
\text { (topology) of biomolecules }\end{array}$ & $\begin{array}{l}\text { Technique cannot be applied } \\
\text { to nanosized crystal, or } \\
\text { crystals with intergrowth and } \\
\text { defects }\end{array}$ \\
\hline $\begin{array}{l}\text { Nuclear Magnetic } \\
\text { Resonance (NMR) } \\
\text { Spectroscopy }\end{array}$ & $\begin{array}{l}\text { High reproducibility and not laborious } \\
\text { sample preparation }\end{array}$ & Low sensitivity \\
\hline $\begin{array}{l}\text { Fluorescence } \\
\text { Activated Cell Sorting } \\
\text { (FACS) }\end{array}$ & $\begin{array}{l}\text { Study heterogeneous populations of cells } \\
\text { at a time }\end{array}$ & $\begin{array}{l}\text { Expensive } \\
\text { Generates excessive data not } \\
\text { always useful }\end{array}$ \\
\hline Western Blotting & High sensitivity and specificity & $\begin{array}{l}\text { Laborious } \\
\text { Expensive } \\
\text { Nonquantitative }\end{array}$ \\
\hline
\end{tabular}

As we can see in Table 1, the widely used analytical methods listed still display technical limitations inherent to their instrument/technique specifications.

In this study, the analytical tool used to carry out protein analysis was electrospray mass spectrometry (ESI-MS). MS has been playing an ever-expanding role in protein structure determination due to is speed, sensitivity, and specificity. A schematic of the basic components of a mass spectrometer is illustrated in Figure 1. [11, 12] 


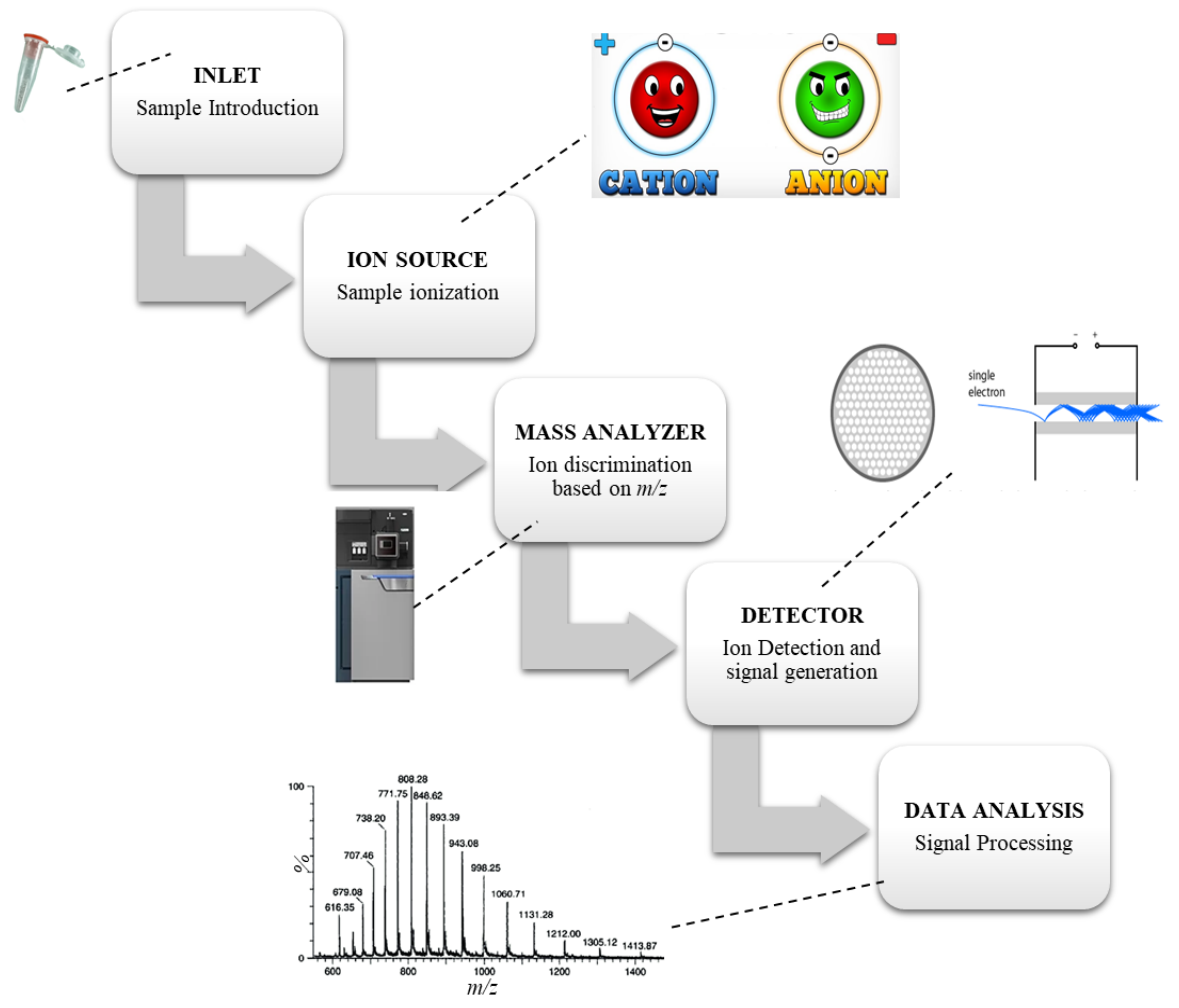

Figure 1. Basic components of a mass spectrometer.

In summary, an assay performed employing MS as the analytical tool should follow the four basics steps as listed below: [13]

1) Ionization of the analyte present in the sample occurs at the ionization source.

2) Ions produced are separated based on their mass-to-charge $(\mathrm{m} / \mathrm{z})$ ratio in the mass analyzer.

3) Separated ions and their abundances are detected, thus generating a response (usually electrical signal) for each species detected.

4) The responses obtained in the detector are converted into signals (peaks) that are shown in a mass spectrum which describes the ions abundances versus their mass-to-charge ratio.

Before the development of "soft" ionization mass spectrometry (MS) techniques, such as electrospray ionization (ESI) and matrix-assisted laser desorption/ionization (MALDI), MS could 
only be used to access small and thermostable analytes that did not result in excess fragmentation of the ions generated. [12] With the introduction of electrospray ESI and MALDI in the late 1980s, MS has become the preferred approach for mass measurement, sequencing, identification, and quantification of proteins, becoming an essential tool in proteomics since ESI can preserve noncovalent bonds during the transition of the proteins from solution to the gas phase. ESI ionizes the analytes out of a solution and is therefore readily coupled to liquid-based (i.e., chromatographic and electrophoretic) separation techniques, which enables the analysis of complex mixtures. Also, ESI often generates multiply charged ions which allows the study of compounds with higher molecular masses, since mass spectrometers measure the mass-to-charge $(\mathrm{m} / \mathrm{z})$ ratio. John B. Fenn received the 2002 Nobel prize in Chemistry for the application of the ESI method to peptides and proteins. $[14,15]$

The ESI ionization process occurs by applying a potential between the spray capillary, which contains the sample, and the entrance aperture to the vacuum of the mass spectrometer, as shown in Figure 2. [16] Once the initial highly charged droplet is emitted from the capillary tip, the solvent evaporates, reducing the droplets size to a point where the charge on the surface of the droplet approaches the Rayleigh limit, the maximum number of charges a droplet of certain size and composition can contain while still being stable. [17] Once the repulsive forces of the charges on the droplet overcome the attractive forces of the solvent ( $75-95 \%$ of the Rayleigh limit) the droplet undergoes fission, creating smaller droplets that undergo the same process until the droplet has been reduced to a size where it contains only one molecule.[18] 


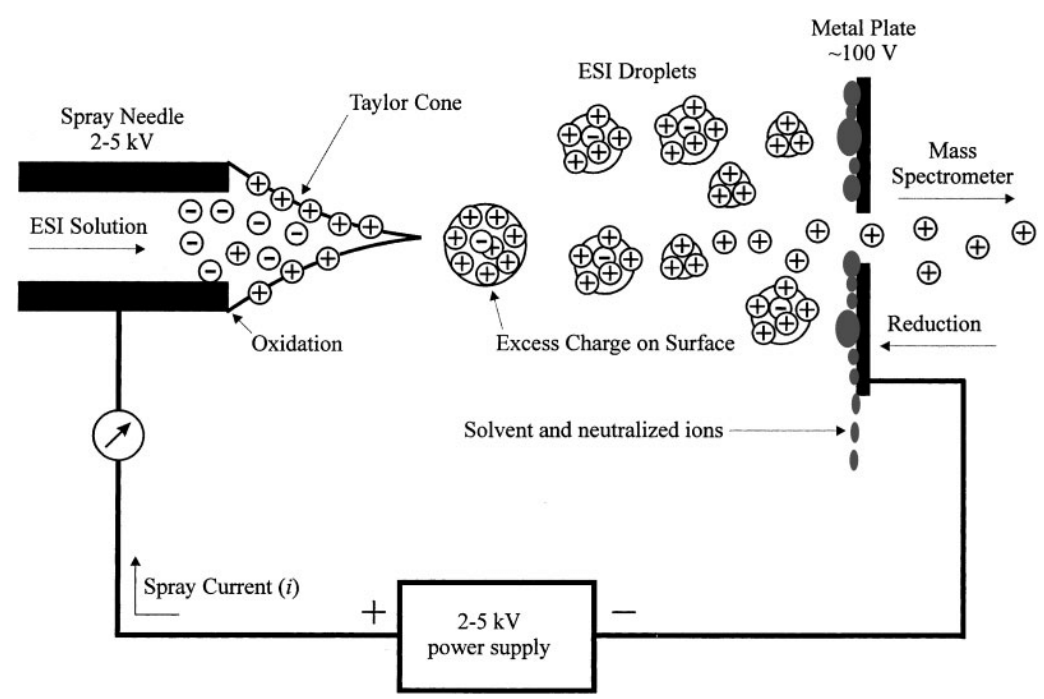

Figure 2. Representation of an ESI source. Reprinted with permission from [16] Copyright 1996 American Chemical Society.

For analysis performed using ESI in positive mode, which is typically used for peptide and protein MS, this means that positively charged (multiply protonated) analytes are enriched in the capillary tip, where electrostatic forces help to overcome the surface tension so that a spray of charged droplets is generated from which the analyte ions are eventually set free. The mechanism of the final step of ESI is still debatable, but for studies involving larger ions such as proteins and peptides, the so-called charge residue model (CRM) has been suggested. CRM proposes that in the finals stages of solvent evaporation the droplet "dries up" and the charge is transferred onto the surface of the analyte, resulting in multiply charged species. [19]

The development of a miniaturized version of Fenn's ESI by Wilm and Mann (Figure 3), named nanoflow electrospray ionization (nanoESI, nESI) showed to be superior for structural assays since it uses much smaller spray tips $(1-10 \mu \mathrm{m}$ diameter, compared to $\sim 100 \mu \mathrm{m}$ for conventional ESI) leading to formation of nanodroplets that requires none or less harsh desolvation conditions. Another advantage of nESI is the possibility of using purely aqueous solutions and volatile buffered solutions (i.e., ammonium acetate or bicarbonate), permitting the control of samples' $\mathrm{pH}$ and creating an environment that is closer to native conditions, if desired, for proteins. $[20,21]$ 


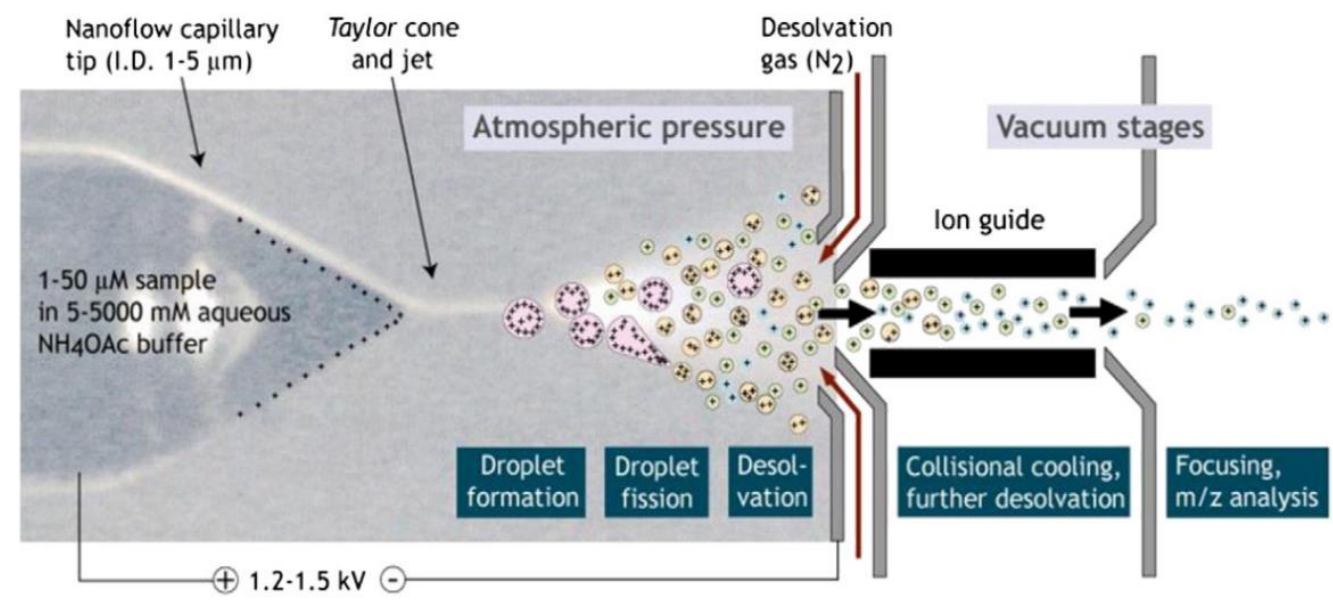

Figure 3. Schematic overview of the n-ESI ionization process. Reprinted with permission from [20].

To fulfill the demand for analytical methods able to perform analysis of a protein within a specific functional macromolecular protein complex in its native environment, a branch of biological mass spectrometry referred to as 'native mass spectrometry' (native MS) was developed. Obtaining MS data of native, functional protein assemblies, or even entire molecular machineries, needs to be performed under certain parameters to preserve the native structures of the biomolecules to allow for intact mass measurements. Native MS is typically carried out using samples prepared in volatile buffers such as ammonium acetate or ethylenediammonium diacetate. [22] The sample volume required for nESI analysis is reduced $(2-5 \mu \mathrm{L})$ at micromolar concentrations that are sprayed at low flow rates $(20-200 \mathrm{~nL} / \mathrm{min})$. Native MS has rapidly expanded, driven by the implicit hypothesis that specific interactions formed by biomolecules in solution can be maintained under carefully controlled conditions for MS analysis in the gas phase. [23]

A crucial advantage of native MS is the possibility to identify the composition and relative abundance of distinct compounds within a macromolecular complex in real time. Applications of native MS, ion mobility/mass spectrometry (IM/MS), and tandem MS (MS/MS) involve probing proteins to obtain information such as their precise stoichiometry, sequence information, direct interactions between subunits, higher order subunit architecture (core vs. periphery) within an assembly, and the strength of inter-subunit interactions. [24-27]

The application of ion mobility spectrometry coupled to mass spectrometry (IM/MS) to studying intact proteins in their native-like conformation was not achieved until the 1990s when Jarrold and Clemmer research groups were the pioneers in the IM/MS field performing analysis of 
atomic clusters and small proteins. Like MS, IM makes measurements on gas-phase ions. However, the above-mentioned IM/MS studies were performed using instruments built in-house, and commercially available IM/MS instruments were only developed later when Waters launched the new hybrid quadrupole/travelling wave ion mobility separator/orthogonal acceleration time-offlight instrument known as Synapt HDMS system. Figure 4 illustrates the instrument used in this study, the second generation of Synapt HDMS developed by Waters Corporation. [28-30]

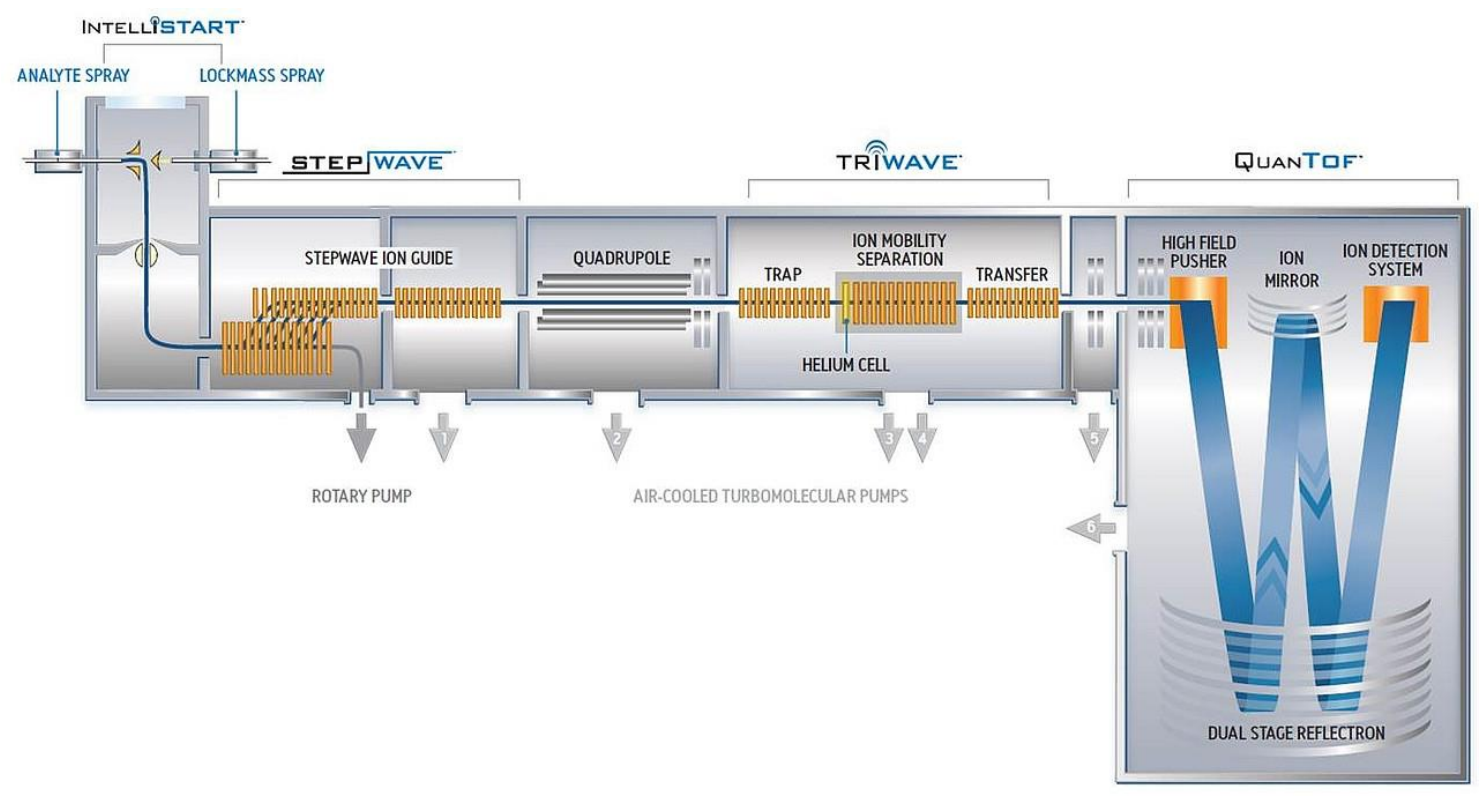

Figure 4. Illustration of Synapt G2-Si High-Definition Mass Spectrometer developed by Waters Corporation.

Time dispersive ion mobility spectrometers all have essentially the same basic principles. A sample is introduced in the IM device via ionization. Next, the packet of ions is separated based on their mobilities when moving through an ion mobility chamber that is filled with a buffer gas (usually helium, argon, or nitrogen) under the influence of an electric field. The mobility of a macromolecular ion is highly conditional on its charge and shape, hence proteins with larger crosssection (proteins presenting larger surface areas) undergo a greater number of collisions with the buffer gas. Consequently, their passage through the mobility cell is retarded in comparison to smaller ions which experience less collisions.

Therefore, collision cross sections (between ion and buffer gas) can be used to evaluate the average projected surface area of all conformers derived from the investigated protein. Thus, the characteristics intrinsic to a protein conformer such as mass, charge, and collision cross section 
determine its mobility under defined IM conditions. As a result, IM coupled to MS can provide biomolecules', mass and overall structure, based on $\mathrm{m} / \mathrm{z}$ and collision cross section values.

Classical IM/MS devices use drift tubes to perform IM separations, where ions are separated based on their difference in size and shape under uniform, static, and low electric field conditions $\left(\sim 2\right.$ V.cm ${ }^{-1}$.Torr $\left.{ }^{-1}\right)$. Since ion mobilities are measured based on the time it takes for a packet of ions to travel the drift tube, reduced mobilities, ion mobilities scaled to the number density at standard temperature and pressure (STP), can be calculated by measuring the drift time, drift voltage, drift tube length, and buffer gas temperature and pressure. The reduced mobility is given by equation 1

$$
K_{0}=\frac{L^{2}}{t_{D} V} \times \frac{273.2}{T} \times \frac{p}{760}
$$

Equation 1

where $\mathrm{V}$ is the voltage drop across the drift tube, $\mathrm{L}$ is the tube length, $\mathrm{t}_{\mathrm{D}}$ is the drift time, $\mathrm{p}$ is the buffer gas pressure in Torr $(1$ Torr $=133.3 \mathrm{~Pa})$, and $\mathrm{T}$ is the temperature of the buffer gas. The mobility values for ions separated using drift tubes can be used to calculate collision cross section values $(\Omega)$ using the Mason-Schamp equation [31]:

$$
\Omega=\frac{3 z e}{16 N} \times\left[\frac{2 \pi}{\mu k_{b} T}\right]^{0.5} \times \frac{1}{K_{0}}
$$

Equation 2

where $\mathrm{N}$ is the buffer gas number density, ze the ionic charge, $\mu$ the reduced mass of the ion-neutral pair, $\mathrm{k}_{\mathrm{b}}$ is Boltzmann's Constant $\left(1.3806452 \times 10^{-23} \mathrm{~J} / \mathrm{K}\right)$, $\mathrm{T}$ the gas temperature and $\mathrm{K}_{0}$ is the reduced mobility. Advantages of IM techniques include simplicity and speed of the analysis, the high selectivity, and the great capacity of the instrument to be miniaturized (portability). [28, 32, 33]

Although drift tube ion mobility influenced the breakthrough of IM studies the technique presented inherent issues such as poor sensitivity due to low duty cycles related to accumulating packets of ions into the tube, leading to an incompatibility with ion sources that use continuous ionization sources. The low sensitivity on drift tubes can also be associated with ion radical diffusion after the diameter of sampling apertures in the mass spectrometer. [30] 
Advances in IM/MS methods focused on addressing the sensitivity issues related to drift tubes, resulting in the development of new approaches to ion mobility separating ions, i.e., traveling wave ion mobility mass spectrometry - TWIMS (Figure 5). [33-35]

a)

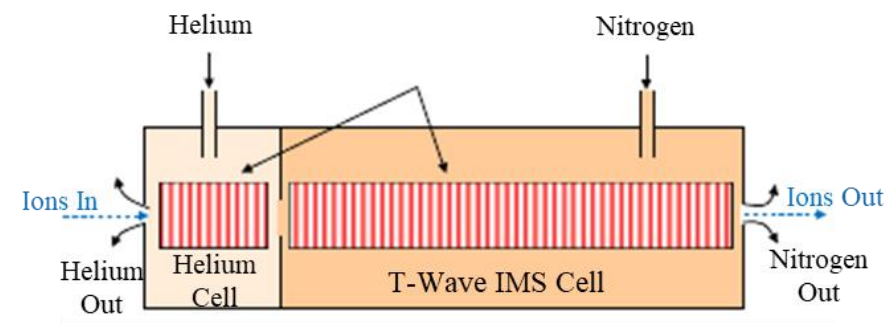

b)
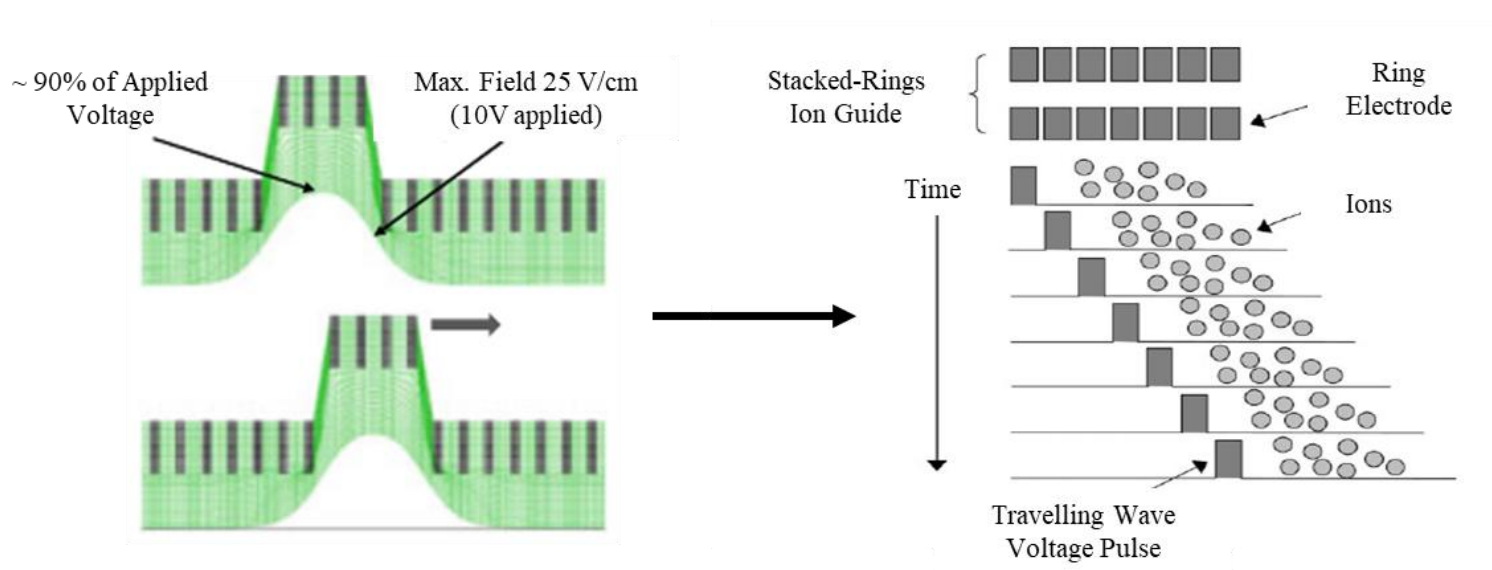

Figure 5. Illustration of ion mobility technique TWIMS, where A) schematic of T-Wave IM cells (The IM T-Wave cell is not depicted to scale), and B) the progression of the travelling wave voltage pulse along the Stacked Ring Ion Guides - SRIG (left) and the 'surfing' of ions on the wave (right). Adapted and reprinted with permission from $[34,35]$.

TWIMS technology employs a traveling square wave potential superimposed on a radiofrequency (RF) stacked ring ion guides (SRIGs). [36] The pseudopotentials generated by alternating phases of RF along SRIGS prevent the radial loss of ions in regions of mass spectrometers where the pressure is relatively high. [36] The IM section presented by the Synapt instrument series (Waters) comprises three SRIGs as shown in Figure 6. [30] 


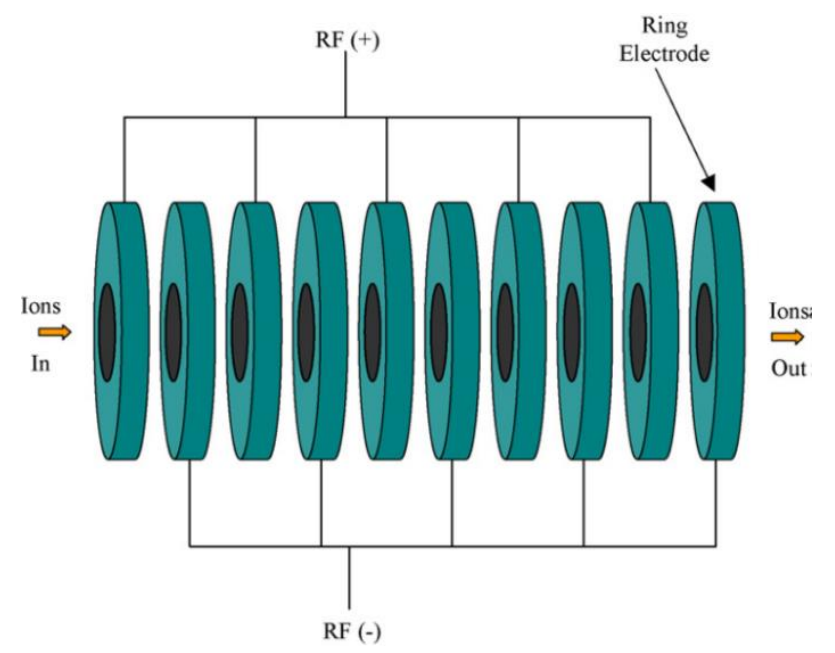

Figure 6. A stacked ring ion guide - SRIG. Reprinted with permission from [30]

In this setup, ions are generated at the ionization source are attracted into the MS inlet, where the ion beam is focused and continuously transmitted under controlled RF fields until it reaches the IM section. After, the ions are accumulated in the trap ion guide, an ions packet is released into the IM ion guide for mobility separation. The transfer ion guide conveys the mobilityseparated ions to the TOF for mass analysis. [30] The mobility separation's arrival time distribution (ATD) is measured by determining the number of TOF mass spectra have been measured since the release of the ions from the trap, with time calculated from the frequency of the TOF mass measurement.

The importance of revealing the behavior and overall structure of native proteins in the gas phase is a consequence of the increasing number of applications of MS-related techniques to structural biology. [37] Hence, it is essential to evaluate protein structures in vacuo after their transition from solution into the gas phase with tools with high structural specificity.

Employing IM/MS in protein structure studies is possible since the proteins' structural properties are encoded into the mass-to-charge ration $(\mathrm{m} / \mathrm{z})$ and the topology of the protein ions. Additionally, changing the $\mathrm{m} / \mathrm{z}$ by modifying the mass of the protein or its proteolytic fragments in a structure-dependent manner gives additional, more localized structural information which can be achieved via ion/ion reactions involving the protein ions and reagents ions. Ion/ion reactions have been exploited for mass spectrometry applications since the beginning of the adoption of electrospray ionization (ESI), using mass spectrometers as the gas-phase analog to the chemist's wet bench. [38-41] Reactions performed in the gas phase when targeting protein identification and 
characterization are only valuable when the reaction products are structurally diagnostic and the reaction efficiency and product ion collection is sufficiently high to be analytically useful. [42] Figure 7 shows the step-by-step of a gas-phase ion/ion reaction performed using a Synapt G2-Si setup. [43]

Solvent-free, gaseous proteins can maintain their solution structures with careful control of experimental parameters. [44-46] Pioneering studies from the laboratories of David Clemmer and Michael Bowers revealed that ubiquitin solution structures can be preserved as kinetically trapped intermediates in the gas phase after evaporative cooling associated with the electrospray process. Their data suggested minor structural changes occur during desolvation of low charge states ions $(\mathrm{z} \cong 7$ ) for native-like conformations, and unfolded gas-phase structures are observed for higher charge states $(\mathrm{z} \cong 13)$ caused by rapid unfolding $(<10 \mathrm{~ms})$. [47]

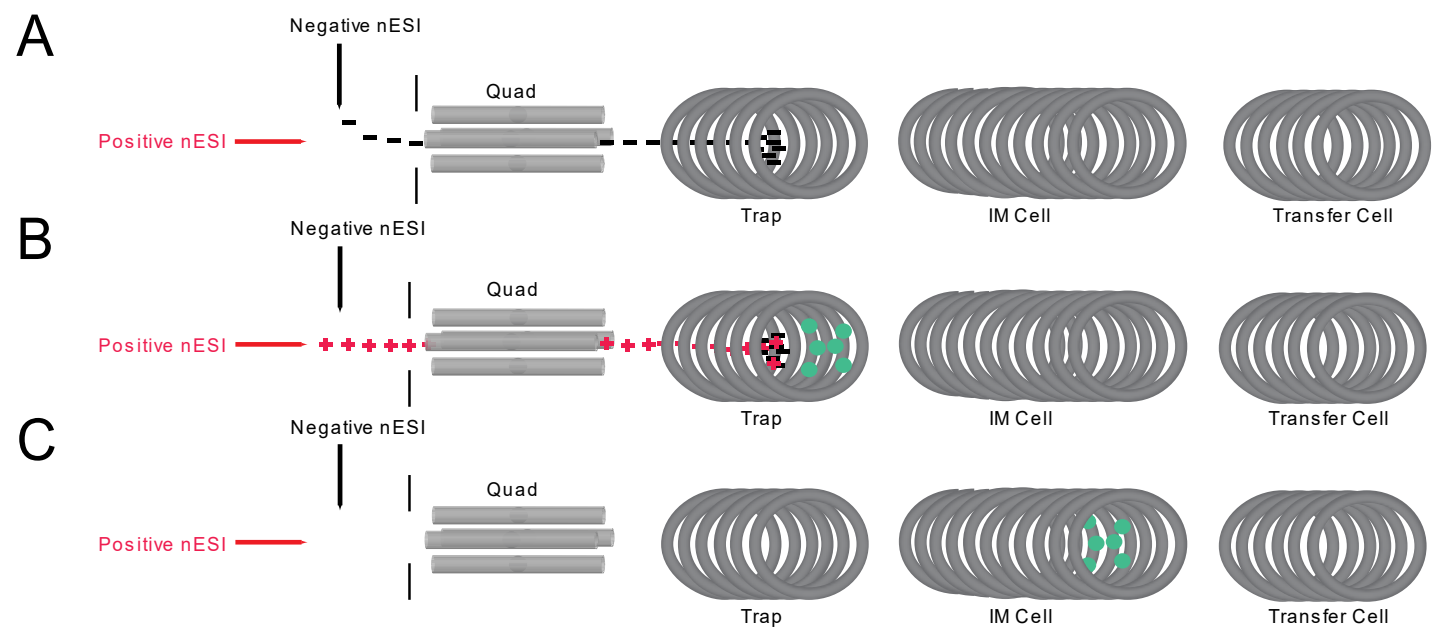

Figure 7. Cartoon illustrating ion/ion reaction sequence. A) Anions (black) and B) cations (red) are introduced into the trap after mass selection, where the ion/ion reaction products (green) form. The bias of the trap can be raised with respect to the IM cell for collisional activation to drive off the leaving group from the covalent reaction (i.e., HOAt). C) Product ions are pulsed into the IM cell to separate products. The product ions are then fragmented by increasing collision energy into the transfer cell. Updated and reprinted with permission from [42].

Different approaches of chemical modifications for protein structure determination have been reported, including H/D exchange [48-54], intra- and intermolecular crosslinking [55-57], and protein structural mapping via covalent labeling [58-63].

Covalent labeling of proteins analyzed by mass spectrometry (CLMS), also known as protein footprinting, is a method widely applied for chemically modifying proteins by labeling 
accessible sites on the surface via formation of new covalent bonds with a designated reagent. [64] CLMS is an example of a reaction that has been transferred from solution [65-67] to the gas phase [68-71]. Covalent modification by gas-phase ion/ion reactions relies on long-lived complex formation between oppositely charged protein and reagent ions which enables the modification of the protein via formation of a new covalent bond. Reagents for covalent modifications are expected to meet the following bifunctional requirements for covalent reactions in gas phase. The functions of an anionic reagent in CLMS includes carrying a "sticky" group (e.g., sulfonate, phosphate, or quaternary ammonium) that creates a strong electrostatic interaction with the analyte ion, resulting in a long-lived stable chemical complex. The anchoring of analyte-reagent complex dictates the efficiency of the covalent modifications, where reactions with high efficiencies will result from formation of a flexible conformational analyte/reagent complex favoring a reactive configuration also allowing for sufficient time for the covalent reaction to occur.

In addition to a sticky group, reagents for covalent modification necessitate a reactive site that will undergo chemical reactions with a functional group in the analyte ion for the covalent chemistry to be completed. Several examples of nucleophilic addition utilizing electrophilic reagents such as reactive esters have been successfully applied. [72] These examples include 4formyl-1,3-benzenedisulfonic acid (FBDSA), [62] N-hydroxysuccinimide (NHS) esters, [73, 74] and, carbodiimide reagents. [75] Figure 8 illustrates the suggested covalent modifications that ubiquitin 5+ undergoes after ion/ion reactions in the gas phase using Sulfo-benzoyl-1-Hydroxy-7azabenzotriazole (Sulfo-benzoyl-HOAt) as the anionic reagent.

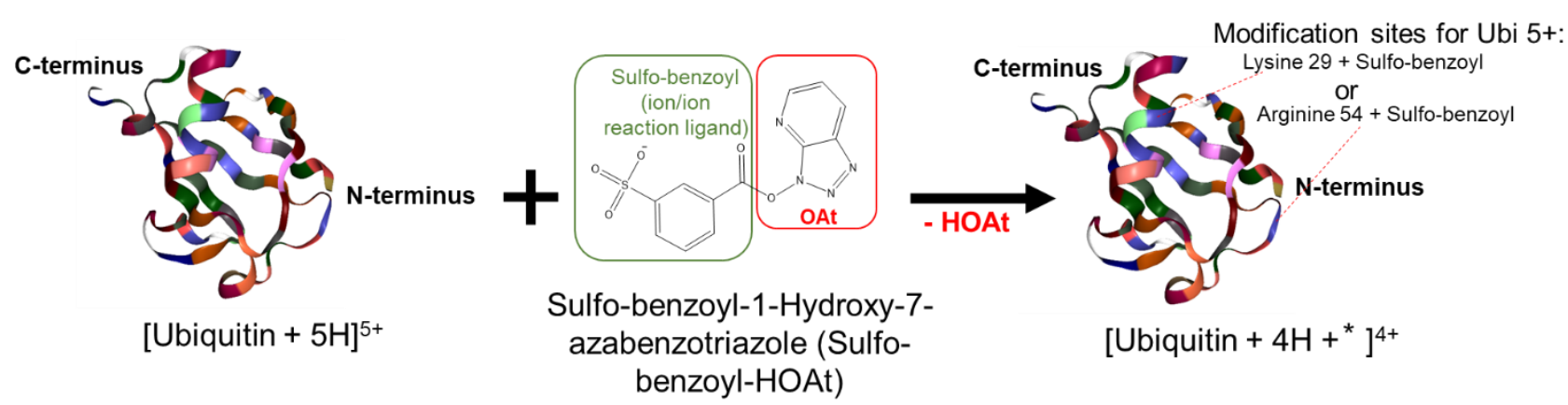

Figure 8. Covalent modification [ubiquitin $+5 \mathrm{H}]^{5+}$ with [sulfo-HOAt $\left.-\mathrm{H}\right]^{-}$generating the product [ubiquitin $++4 \mathrm{H}+*]^{4+}$ via ion/ion reaction performed in the gas phase. 
CLMS provides insight about protein conformations, [76] dynamics, and amino acid residue reactivity and microenvironment. [77] CLMS conducted in a tandem mass spectrometer through ion/ion reactions has the advantages of independent control/optimization of reactant species, high versatility based on the variety of reagents and proteins sites involved, real-time comparison between modified and unmodified forms of the protein, well-defined reaction conditions, reagent purification through mass-to-charge isolation, and tandem MS capabilities in conjunction with ion/ion reactions. [71, 78]

A distinctive feature of some reagents utilized in CLMS assays is the possibility of exploring protein folding reactions in a $\mu$ sec timescale, which is not accessible by most analytical tools. [72, 79] Hence, ion/ion covalent labeling coupled to IM-MS/MS can, in principle, provide for the three-dimensional characterization of gaseous protein ions. [80, 81]

In this work, we focused on the three-dimensional characterization of gaseous ubiquitin ions with CLMS performed completely inside the mass spectrometer. We chose ubiquitin as the protein analyte for this assay because it exhibits a small size (76 amino acid residues), and has been well characterized experimentally and theoretically by a variety of methods such as, but not limited to, circular dichroism (CD), [82, 83] hydrogen exchange, [84-87] Nuclear Magnetic Resonance, [88-91] calorimetry, [92-94] molecular dynamics simulations, [95-99] Hydrogen Bond Scalar Couplings, [100, 101] capillary electrophoresis, [102] X-ray Crystallography, [103, 104] HPLC, [105-107], and Mass Spectrometry [47, 48, 108-115].

The bovine form of ubiquitin is comprised of 76 residues with the sequence showed in Figure 9. Ubiquitin is present in all eukaryotic cells and its biological role is to direct the movement of important proteins in the cell, promoting synthesis of new proteins and proteasomal degradation, usually aiming to control protein load in the cells. The destruction of cells by ubiquitin occurs via a signaling process called ubiquitination, where successive covalent additions of ubiquitin molecules occur to designated proteins. [116, 117]

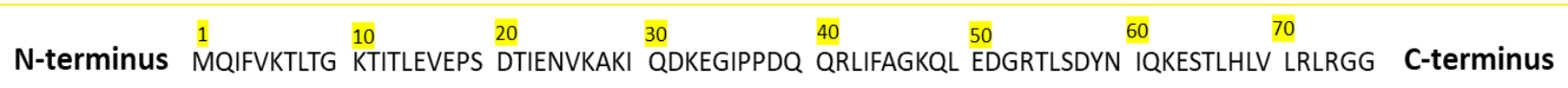

Figure 9. Sequence of bovine erythrocytes ubiquitin.

Ubiquitination is a post-translational modification that creates an isopeptide bond between a lysine residue on the protein and the carboxyl terminus of ubiquitin, producing a multiubiquitin 
chain that is recognized by a proteasome for further degradation of the whole complex. The ubiquitin proteasome system (UPS) is the major regulator of programmed protein destruction in human cells. [118-120]

Additional studies evaluated the abundance of different conformations of ubiquitin in the gas phase as a function of methanol content in solution, where the native state (N-state) was favored in aqueous solutions and more elongated states of ubiquitin (A- and U-states) were dominant in solutions of 20:80 water:methanol content. The favored conformations of ubiquitin in the Native-state, A-state, and Unfolded-state are illustrated in Figure 10. [47, 121]
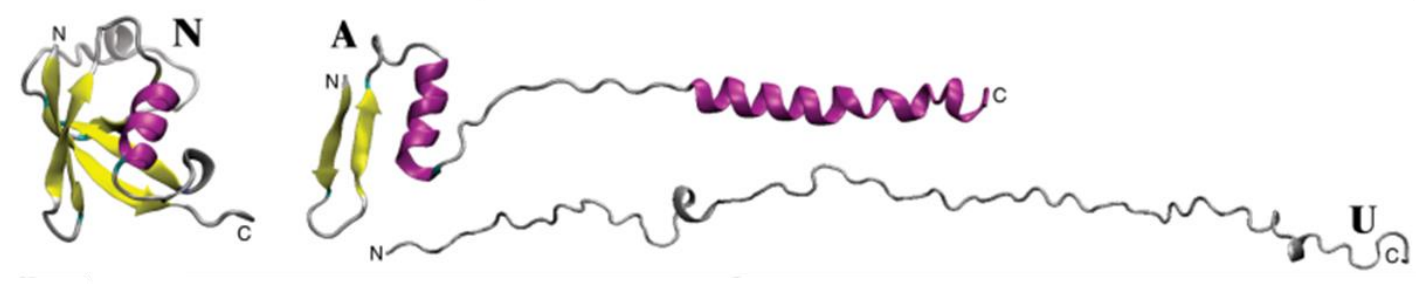

Figure 10. Conformations of the protein ubiquitin, where $\mathrm{N}$ represents the native-state, $\mathrm{A}$ is the A-state, and $\mathrm{U}$ is the U-state. Updated and reprinted with permission from [92].

The native state of ubiquitin presents a tightly folded structure incorporating $\alpha$-helix and $ß$-sheet secondary structure elements, where both ends of the polymer chain, $\mathrm{N}$ - and $\mathrm{C}$-terminus, are held together by a ß-strand between residues Gln2-Lys6 and Thr66-Leu71. [47] Ubiquitin in the native-like form is very stable, with a remarkably rigid backbone structure, and occurs under a broad range of solutions conditions. The N-state has been substantially addressed using highresolution structural tools, i.e., X- ray crystallography, NMR spectroscopy, IM-Mass Spectrometry, and dynamically using NMR relaxation measurements, transient 2D IR spectroscopy, molecular dynamics, and so on. [122-128]

The A-state of ubiquitin is a partially folded structure detectable above a $30 \%$ methanol: water volume ratio and the major populated structure in methanolic acidic solutions $(\mathrm{pH} \sim 2)$ containing methanol: water ratios of $60 \%$ in volume/volume or higher. For the A form of ubiquitin, it is suggested that most of the native-like secondary structural elements are maintained in the $\mathrm{N}$ terminal half (residues 1-35) of the protein. On the other hand, the C-terminal half (residues 3676) for the A state is believed to unfold transitioning to a more elongated shape ( $\beta$ to $\alpha$ transition), deviating from its native structure, probably related to disruption of the salt bridges Lys11/Glu34, 
Lys27/Glu51, and Lys27/Asp52 anchoring the two termini of the $\alpha$-helix and the $\beta$-sheet. [129, 130] Therefore, its understood that the A state of ubiquitin consists of $\beta$-hairpin, a native-like $\alpha$ helix, and two nonnative $\alpha$-helices, forming an extended $\alpha$-helical structure connected by flexible linkers. [100, 129]

In solutions with methanol content higher than $95 \%$ in volume, a new population of ubiquitin ions exhibiting more extended structures named unfolded state (U-state) becomes noticeable, whereas the extent of population A state ions decays. [130, 131] The U-state was established as a near linear structure, being the final annealed gas phase geometry for ubiquitin cations $(\mathrm{z}=13) \cdot[47,132]$

Gerber and coworkers simulated the conformational evolution of ubiquitin ions $\left(13^{+}\right)$ during unfolding processes via high temperature molecular dynamics simulations (MD) [97]. Their outcomes suggested the presence of intermediate structures (I1 and I2) existing between the Astate and U-state, based on the different conformation transitions of the ionic populations.

The U-state presented virtually no secondary structure and was achieved after the following transitions: [97]

1) A state transition to the I1 state occurs via disappearance of the helical structure in the range of residues Gln41/Gly76.

2) I1 state transition to the $I 2$ state occurs after simultaneous unzipping of the N-terminal B-sheet., where the hydrogen bond connecting $\mathrm{N}$-terminal ammonium group and the carbonyl oxygen of Glu16 is disrupted.

3) Finally, the transition resulting in the final most extended U-state occurs after hydrogen bond disruption among Lys11/Glu34.

As a result, the U-state consists of a short $\alpha$-helical segment with an almost fully unfolded backbone for the rest of the molecule.

Bowers and coworkers also described the more extended states of ubiquitin for $[\mathrm{M}+9]^{9+}$ to $[\mathrm{M}+13]^{13+}$ ions as a group of four families of elongated structures $(\mathrm{E})$ that emerged from the Astate denominated E1, E2, E3, and E4, where E1=A-state, E2 and E3 are intermediate structures, and $\mathrm{E} 4$ as being the most elongated conformation with nearly no secondary structure. [47] 
Methodologies to identify proteins and their modification sites using tandem mass spectrometry can be discussed in terms of the entities that are subjected to mass analysis and can be divided into two well established categories referred as 'bottom-up' and 'top-down' approaches. [42] A schematic illustrating the major differences existing between these techniques is shown on Figure 11. [133]

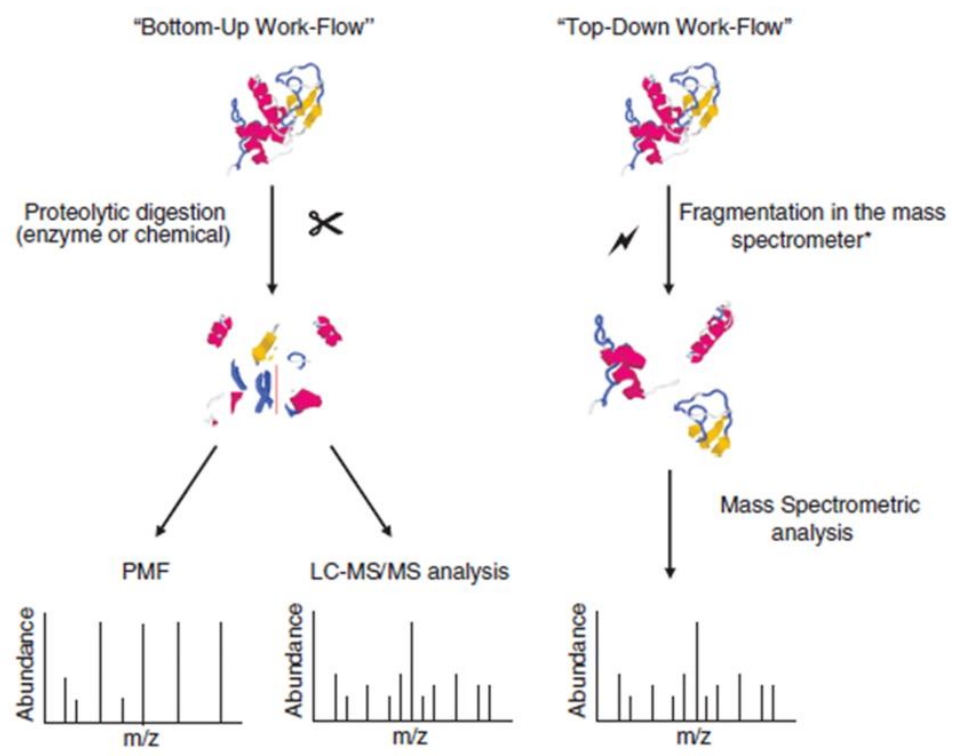

Figure 11. Representation of the basic differences between the 'top-down' and 'bottom-up' techniques. Reproduced with permission from [76]

For 'bottom-up' approaches, the identification of proteins occurs via tandem mass spectrometry analysis of individual peptide ions that were obtained using chemical or proteolytic cleavage of the protein prior to MS analysis. A conventional 'bottom-up' assay is generally initiated by electrophoretic separation of a protein mixture followed by in situ proteolysis of an individual protein. [11, 134] The peptides generated are extracted and submitted to direct MS analysis, providing insight about peptide 'mass fingerprint' which is compared to existing database for comparison and diagnostic for protein identification. [135, 136]

This approach relies on the purity of the protein sample, the specificity of the proteolysis approach, and the quality of the mass measurement. For quantitation of a specific protein present in a complex mixture, each peptide that was derived from the proteolytic process is submitted to tandem mass spectrometry (MS/MS) analysis, leading to identification of each peptide in question, and therefore the protein of origin. 
"Bottom-up" methodology relies on identifying the protein identity by searching protein sequence database analysis of the uninterpreted product ion spectra [137], by 'de novo' sequence analysis, [138] or via searching for a limited stretch of amino acid sequence through a 'sequence tag' database. [139] Limitations associated to 'bottom-up' technique account for the laborious sample preparation and protein purification processes required prior to proteolysis, loss of protein information during digestion process since many of the peptides generated from proteolysis are not observed upon MS analysis, and a time consuming data investigation process due to the extent number of proteolytic peptides produced from digestion of an intact protein. [140]

The aforementioned 'top-down' approach in proteomics was developed in order to obtain primary structural information directly from the gas-phase dissociation of whole protein ions via MS/MS analysis without prior extensive separations or digestion. [141] McLafferty and coworkers published one of the pioneering studies comparing both techniques, 'top-down' and 'bottom-up' for protein characterization. [142]

In 'top-down' experiments, protein identification is made by analyzing protein sequence fragments of intact proteins from tandem MS, which allows for the examination of the complete amino acid sequence, enabling characterization of intact proteins and identification of the number and kinds of post-translational and other modifications in various so-called proteoforms, major advantages of this method. [143-145]

The structures of gaseous ubiquitin generated from both aqueous and denaturing conditions were evaluated using ion/ion chemistry, top-down tandem mass spectrometry, and ion mobilityderived collision cross section measurements. Covalent labeling reactions between ubiquitin and sulfo-benzoyl-1-hydroxy-7-azabenzotriazole ester (sulfobenzoyl-HOAt, Figure 8) were performed in the trap cell of a quadrupole IM-MS. The reaction results in the formation of amide bonds with primary amines and guanidine bound to sulfobenzoate in the gas-phase.

The covalently modified protein ions are separated by the number of additions of the reagent by ion mobility and fragmented with mass analysis of the fragmentation products. Mass shifts in the sequence fragments due to the covalent addition of the sulfo-benzoyl moiety allow for identification of covalently labeled sites. The results demonstrate the power of a combined collision cross section and covalent labeling approach to detect changes induced by solution conditions with measurements conducted entirely in the gas phase. 


\section{CHAPTER 2. MATERIALS AND METHODS}

\subsection{Materials}

Methanol, N,N-dimethyl formamide (DMF), and formic acid were purchased from Fisher Scientific (Fairmont, NJ). Ubiquitin from bovine erythrocytes, myoglobin from horse heart, cytochrome c from equine heart, and ammonium acetate were purchased from Sigma-Aldrich (St. Louis, MO). 1-Hydroxy-7-azabenzonitrazole (HOAt) was purchased from TCI America (Portland, OR). 1-Ethyl-3-(3-dimethylaminopropyl) carbodiimide hydrochloride (EDC) was purchased from Thermo Scientific (Rockford, IL). 3-Sulfobenzoic acid monosodium salt was purchased from Alfa Aesar (Ward Hill, MA).

\subsection{Sample Preparation}

For the experiments performed in denaturing conditions ubiquitin was dissolved in a $50 / 50 / 0.1 \mathrm{vol} / \mathrm{vol}$ solution of water/methanol/formic acid at $1 \mu \mathrm{M}$. For analysis using aqueous conditions, ubiquitin was dissolved in an aqueous $10 \mathrm{mM}$ ammonium acetate solution at $1 \mu \mathrm{M}$.

The reagent used for the ion/ion reactions, sulfobenzoyl-HOAt, was synthesized by combining $10 \mu \mathrm{L}$ of $100 \mathrm{mM}$ EDC, $100 \mathrm{mM}$ sodium 3-sulfobenzoate, and $100 \mathrm{mM}$ HOAt in DMF, then the solution was diluted 100x with acetonitrile and infused directly to the nESI source. [146] The calibrant mix used for CCS calculations consisted of $1 \mu \mathrm{M}$ ubiquitin, cytochrome $\mathrm{C}$, and myoglobin in 50:50:0.1 (v/v) solution of methanol/water/formic acid.

\subsection{Calibration of Travelling Wave-Ion Mobility Spectrometry Drift Times}

Calibration of drift time measurements to known collision cross section values is necessary for traveling wave-type IM instruments that use time-varying electric fields within the drift region. Traveling-wave drift times for ubiquitin conformers present in denaturing and native samples were calibrated by measuring TWIMS profiles of a calibrant mix containing analytes with known CCS values for each set of experiments following a previously published protocol. [147-150]

IM-MS data for the calibrant mix and for ubiquitin ions was obtained using precisely the same instrument conditions to avoid affecting the recorded drift time between calibration runs and 
measurements of ubiquitin. The instrument settings used in CCS measurements and ion/ion reactions are summarized in Table 2.

A calibration curve (Figure 12) was obtained by plotting natural logarithm of the nitrogen CCS [149] to charge ratios versus the calibrant ion drift times obtained experimentally. The data was fit with a power function of the form given by Equation 3, where $\mathrm{CCS}_{\mathrm{N} 2}$ is the calibrant nitrogen CCS value from the database, $\mathrm{z}$ is the charge state of the ion, and $\mathrm{t}_{\mathrm{d}}$ is the drift time found experimentally.

$$
\ln \left(C C S_{N_{2}} / z\right)=a t_{d}^{b}
$$

The constants a and b, shown in Equation 3 were used to calculate nitrogen TWIMS CCS values for ubiquitin species from measured drift times according to Equation 4.

$$
C C S=z * e^{a t_{d}^{b}}
$$

Equation 4

Where $t_{d}$ is the drift time obtained for the ubiquitin conformers used to perform the ion/ion reactions, $\mathrm{z}$ is the ubiquitin charge state present in native and denaturing samples, and $\mathrm{a}$ and $\mathrm{b}$ the variables acquired from the data fitting. The CCS values were reported as the average obtained from triplicate measurements in Tables 3 and 4. All the CCS calibration calculations and results were reported as recommended by recently introduced criteria. [151] 


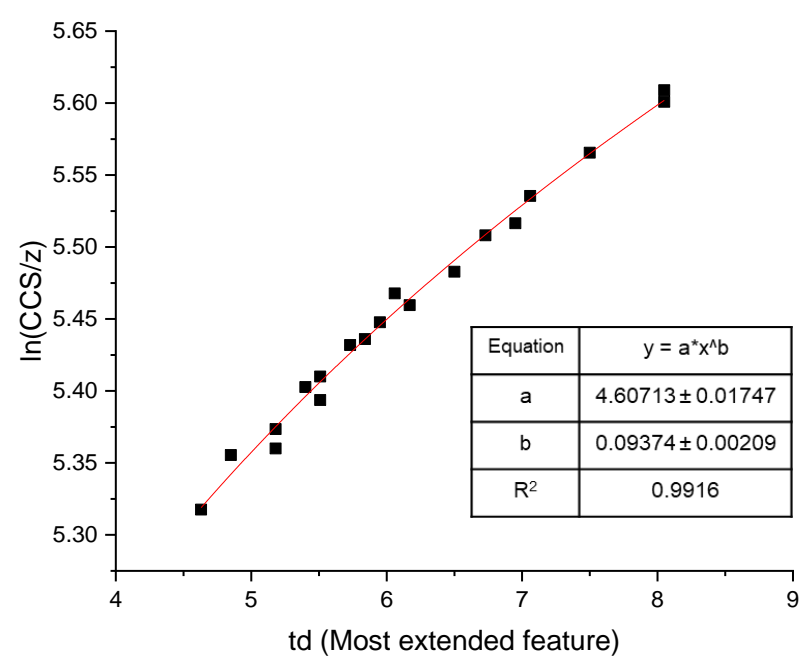

Figure 12. Calibration curve obtained by plotting natural logarithm of the nitrogen CCS to charge ratios versus the calibrant ion drift times.

\subsection{Mass Spectrometry and Ion/Ion Reactions}

Experiments were performed on a Synapt G2-Si High Definition Mass Spectrometer (Waters Corporation, Wilmslow, U.K.) furnished with electron transfer dissociation (ETD) and a NanoLockspray source. The instrumental arrangement for the ion/ion reactions performed has been previously described. [152] Briefly, the source contains two nanoelectrospray (nESI) probes positioned normal to each other and the sampling cone. The nESI baffle was removed. Sequential anion (sulfobenzoyl-HOAt) and cation (ubiquitin) ionization was enabled by a WRENS (Waters Research Enabled Software) script coupled with ETD mode to synchronize ion injection with the polarity of the instrument optics and ETD refill times (1s each) for reagent and cation fills, respectively. Infusion flow rates were $500 \mathrm{~nL} / \mathrm{min}$ or lower.

The control sequence consists of injecting ions through the step wave region with $\mathrm{m} / \mathrm{z}$ isolation in the quadrupole. Anions are trapped in the trap cell in the first step, followed by introduction of a specific analyte (cationic) charge state (again, $\mathrm{m} / \mathrm{z}$ isolated by the quadrupole) into the trap. Next, reaction products are pulsed out of the trap, separated by their mobilities, and then traverse the transfer cell where the transfer collision energy is increased allowing for collision induced dissociation (CID) after the reaction products exit the mobility cell. 
Thus, ion/ion reactions products and their sequence fragments share identical drift times since fragments were not generated until after IM separation. Ions were mass analyzed by the timeof-flight mass spectrometer in Resolution Mode (nominal resolving power of 20,000 FWHM). Tandem mass spectra were internally calibrated against the monoisotopic mass of the $\mathrm{y}_{18^{2+}}$ fragment ion from ubiquitin $(\mathrm{m} / \mathrm{z}$ 1049.0997) via MassLynx Software.

\subsection{Data Analysis}

Mobility-selected mass spectra were extracted with the instrument control software MassLynx V4. Extracted mass spectra were converted into .mgf (Mascot Generic Format) files and imported into Mash Explorer, [153] where spectra were deconvoluted by the eThrash algorithm [154] with a $\mathrm{S} / \mathrm{N}$ threshold of 3, peak background ratio of 1 , and peptide minimum background ratio of 1 and minimum isotopic fit $\%$ of 80 . The covalently modified and unmodified CID fragments obtained for all experiments were investigated against the ubiquitin primary sequence by applying custom PTMs equal to the mass of the covalent modification formed by the ion/ion reactions (i.e., $182.98 \mathrm{Da}$ ) at the $\mathrm{N}$ and $\mathrm{C}$ termini. Covalently modified peaks were annotated with a mass error tolerance of $20 \mathrm{ppm}$. [155] The annotations were then manually confirmed. 


\section{CHAPTER 3. RESULTS AND DISCUSSION}

\subsection{Protein Mass Spectra}

Previously published research by Loo, et al., analyzed a range of biomolecules samples by electrospraying proteins solutions, including ubiquitin, comprised of varying solvent systems, such as the solution $\mathrm{pH}$ or composition, revealed that the distribution of the ions charge states was dependent on the properties of the solution. [156] Nano-Electrospray ionization of $1 \mu \mathrm{M}$ ubiquitin dissolved in an aqueous $10 \mathrm{mM}$ ammonium (Figure 13, top) and in solution of 50/50/0.1 vol/vol solution of water/methanol/formic acid (Figure 13, bottom) result in spectra with distinct properties, i.e., peak distribution profiles and absolute intensities.

Mass spectra for both experiments were generated by analyzing the samples under the "softest" instrument conditions that allowed enough ion transmission to collect mass and mobility spectra without disrupting the protein structure in the gas phase. The tune settings used in this study are represented in Table 2.

The mass spectrum of ubiquitin electrosprayed for the buffered aqueous solution is shown in Figure 13 (top). At native state, a profile of high $\mathrm{m} / \mathrm{z}$ signals is observed, presenting lower charge states (i.e., $6 \geq z \geq 4$ ) peaks with the $6^{+}$being the predominant charge state.

For the denaturing solution, a bimodal charge state distribution was found presenting a shift in the charge state distribution to higher charge state peaks ( $13 \geq z \geq 5$ ) when compared to the profiles obtained for aqueous solution, with the charge state distribution centered at the $10^{+}$charge state. Ubiquitin sequence contains 13 basic sites, which are the N-terminal amino group, one histidine $(\mathrm{H})$, seven lysine $(\mathrm{K})$, and four arginine $(\mathrm{R})$ residues; hence it can accommodate up to 13 protons when being analyzed by ESI. [157] Thus, the change in ions populations is consistent with the expected species to be analyzed in native and denaturing conditions. [158] 

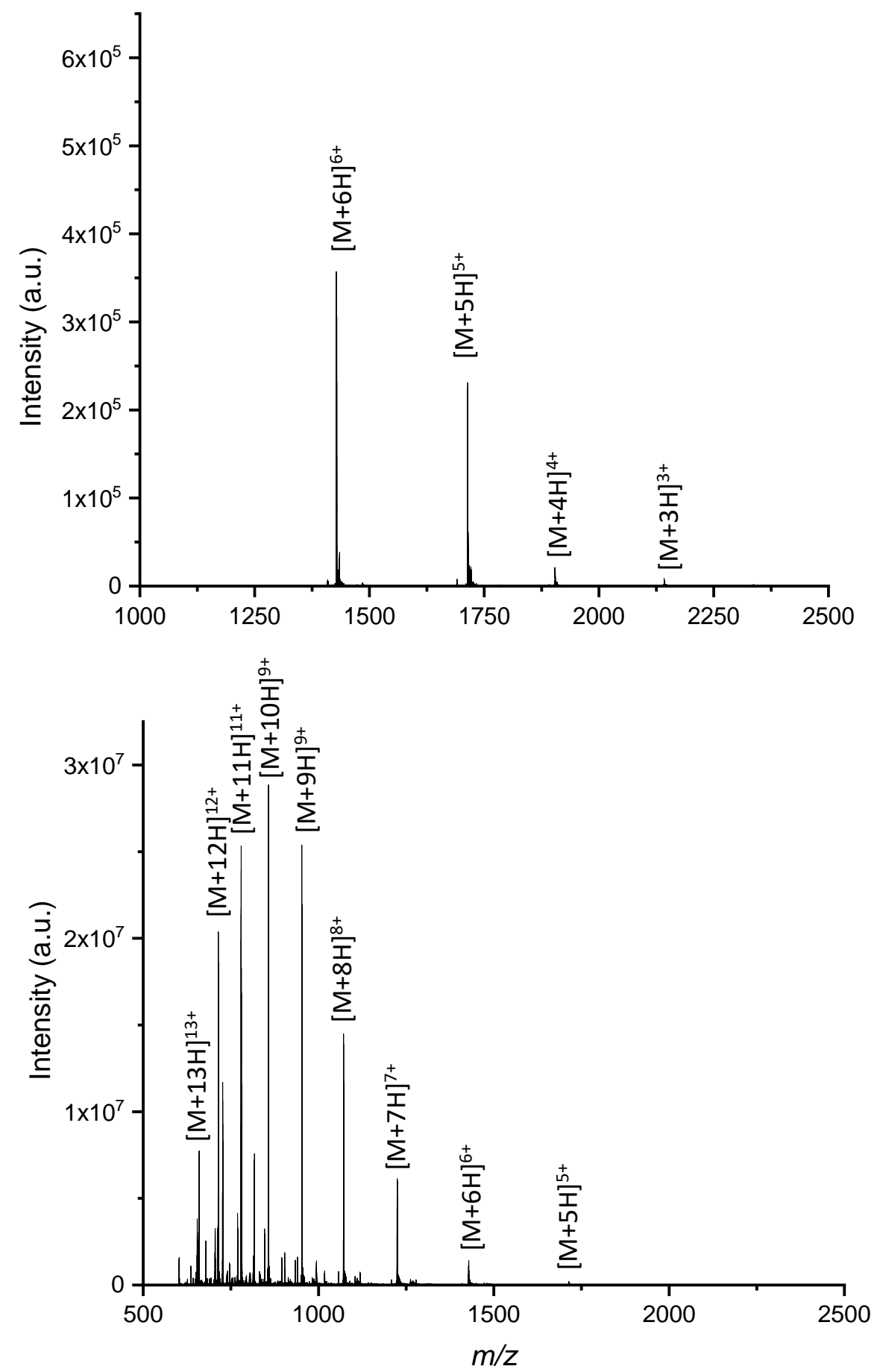

Figure 13. Mass spectra for ubiquitin electrosprayed from (top) native and (bottom) denaturing solution conditions used for CCS calibration and ion/ion reactions. 
Table 2. The instrument settings used in CCS measurements and ion/ion reactions for native and methanolic ubiquitin samples, and the calibrant mix.

\begin{tabular}{|c|c|c|c|c|}
\hline \multicolumn{2}{|c|}{ Instrument Parameters } & \multirow{2}{*}{$\begin{array}{c}\text { Native Samples } \\
1.5\end{array}$} & \multirow{2}{*}{$\begin{array}{c}\text { Methanolic samples } \\
2.00\end{array}$} & \multirow{2}{*}{$\begin{array}{r}\text { Calibrant mix } \\
1.63\end{array}$} \\
\hline Source & Capillary (kV) & & & \\
\hline & Sampling cone & 10 & 10 & 10 \\
\hline & Source offset & 10 & 10 & 10 \\
\hline & Temperature $\left({ }^{\circ} \mathrm{C}\right)$ & 120 & 120 & 120 \\
\hline \multirow[t]{2}{*}{ Source Ion Guide } & Wave velocity $(\mathrm{m} / \mathrm{s})$ & 300 & 1000 & 1000 \\
\hline & Wave Height (V) & 0 & 20 & 20 \\
\hline \multirow[t]{2}{*}{ RF settings } & Stepwave & 320 & 320 & 320 \\
\hline & Ion guide & 300 & 300 & 300 \\
\hline \multirow[t]{3}{*}{ Mobility Trapping } & Release time $(\mu s)$ & 500 & 500 & 500 \\
\hline & Trap height (V) & 12 & 12 & 12 \\
\hline & Extract height (V) & 8 & 8 & 8 \\
\hline \multirow[t]{2}{*}{ IMS } & Wave velocity (m/s) & 800 & 800 & 800 \\
\hline & Wave Height (V) & 40 & 40 & 40 \\
\hline \multirow[t]{2}{*}{ Transfer } & Wave velocity $(\mathrm{m} / \mathrm{s})$ & 200 & 170 & 170 \\
\hline & Wave Height (V) & 5 & 5 & 5 \\
\hline \multirow[t]{3}{*}{ Trap DC } & Entrance & 3 & 3 & 3 \\
\hline & Bias & 23.5 & 30 & 30 \\
\hline & Trap DC & -10 & -10 & -10 \\
\hline \multirow[t]{4}{*}{ IMS DC } & Entrance & 11.5 & 11.5 & 11.5 \\
\hline & Helium cell DC & 15 & 20 & 20 \\
\hline & He cell exit & -15 & -15 & -15 \\
\hline & Bias & 5 & 5 & 5 \\
\hline \multirow[t]{2}{*}{ Transfer DC } & Entrance & 5 & 5 & 5 \\
\hline & Exit & 15 & 15 & 15 \\
\hline \multirow[t]{2}{*}{ Triwave Trap } & Wave velocity (m/s) & 300 & 300 & 300 \\
\hline & Wave Height (V) & 0.1 & 0.1 & 0.1 \\
\hline \multirow[t]{3}{*}{ Gas controls (mL/min) } & Trap & 20 & 0.8 & 20 \\
\hline & Helium cell & 200 & 200 & 200 \\
\hline & IMS & 80 & 80 & 80 \\
\hline
\end{tabular}


A comparison of the extent of peaks present in both analyses of native and denaturing samples of ubiquitin indicates that in native conditions the native globular form of the protein dominates $\left(5^{+}\right.$and $\left.6^{+}\right)$and there is no evidence of the presence of other ion species in the spectrum. On other hand, the spectrum obtained from denaturing conditions reveals the presence of signals that do not pertain to the electrosprayed signals of ubiquitin. This result suggests that small neutral losses, such as $\mathrm{H}_{2} \mathrm{O}, \mathrm{NH}_{3}$ (or $\mathrm{OH}^{-}$), $\mathrm{CO}$, and $\mathrm{COOH}^{-}$, are observed for the precursors of the ubiquitin ions. Neutral-losses are associated to the charge of the precursor, which means that precursors with distinct charge states will be showing different neutral losses signals, even if they generate the same loss. [159] This fact could explain the presence of several other peaks not related to the major ubiquitin ions. Williams and coworkers suggested that losses of small neutral molecules appear to be occur via rearrangement reactions of the ion when in denaturing conditions [160]

The charge state profile observed from the methanolic solution presented higher absolute intensities to those observed from the aqueous solution. The throughput of ions analyzed by ESI in the positive ion mode can be influenced by the solvent system, the process of charging the analyte, the analyte surface activity, structural characteristics and concentration of the analyte, and instrumental parameters. [161-163]

Cech and Enke previously stated that to achieve a stable ESI spray capable of yielding spectra with good ratio of analyte signal-to-noise in the positive mode is to have at least $50 \%$ of a moderately polar organic solvent such as methanol or acetonitrile with the rest of the solvent being aqueous. They also claimed that if the solution presents a higher water percentage than $50 \%$ it would increase the surface tension on the Taylor cone, interfering with the spray formation. [164] The results noted for the absolute intensities of ions generated from methanolic and buffered solutions corroborate with the literature, though we note that starting off with smaller droplet sizes from, e.g., nESI, can assist with ionization of aqueous solutions.

The charge state distributions suggest that ubiquitin ions electrosprayed under aqueous conditions have a compact solution structure, as supported by the literature. [37,165] The compact native state of ubiquitin has a limited number of amino acid residues accessible for protonation. On other hand, the higher charge states exhibited for denaturing conditions is evidence of the disruption of the tertiary structure of ubiquitin. [166-168] The observed transition in charge state distributions indicates that methanol induces structural transitions for ubiquitin. 
The discrepancies found in these mass spectra upon altering the solution composition, such as charge state distribution, signal intensities and peak distribution profile, are analogous to data reported previously for ubiquitin. [169]

\subsection{Gas-Phase Ubiquitin Conformations in the Trap Cells from Native and Denaturing Conditions}

To compare ubiquitin conformations generated from different solution conditions, calibrated collision cross sections were measured for each of the charge states that were investigated by covalent labeling with both denaturing and aqueous conditions (Tables 3 and 4). The necessity of investigating the ions' conformations that are involved in the ion-ion reactions is due to the high degree of structural heterogeneity demonstrated by proteins when analyzed by IMMS, the unique CCS values showed for each of the multiple charge states resulting from the ESI process as well as the CCS values obtained in different drift gases, for example those obtained in nitrogen and helium gases. [47, 170, 171]

Ubiquitin conformers originating from aqueous and denaturing conditions were assessed by converting the centroids of the peaks in the ion mobility arrival time distributions (ATDs) to CCS values allowing for the characterization of ubiquitin populations that undergo ion/ion reaction chemistry. The CCS values were calculated as outlined in the Equations 1 and 2, in the Methods section (Chapter 2). The \%CV values for the calibrated CCS values measured on three different days were less than $2.5 \%$. The equation 5 was used to calculate $\% \mathrm{CV}$.

$$
\% C V=\left(\frac{\text { Standard Deviation }}{\text { Mean }}\right) \times 100 \quad \text { Equation } 5
$$

Thus, we are chiefly concerned with the ion populations present in the trap cell prior to the ion mobility separation, as these are the populations directly probed by the ion/ion reactions. Therefore, we minimized the trap and mobility voltages to prevent instrument-induced structural transitions or unintended activation that might be triggered by energetic collisions of the ions in the gas phase. [172] The experimental conditions applied for CCS calibration and ion/ion reactions were identical (with exception of the gas flows into the helium and mobility cells) and are summarized in Table 2. 
Table 3. CCS values, average, and standard deviation results calculated for the less extended conformations of ubiquitin ( $1^{\text {st }}$ peak) for both native and methanolic conditions.

\begin{tabular}{lccccccc}
\hline $1^{\text {st }}$ peak & \multicolumn{7}{c}{ CCS VALUES $\left(\AA^{2}\right)$} \\
\hline & Charge States & $1^{\text {st }}$ day & $2^{\text {nd }}$ day & $3^{\text {rd }}$ day & AVERAGE & STD DEVIA & $\%$ CV* $^{*}$ \\
\hline & $5+$ & 1233 & 1174 & 1173 & 1193.333 & 28.05153987 & 2.350688 \\
\cline { 2 - 8 } NATIVE & $6+$ & 1268 & 1205 & 1225 & 1232.667 & 26.28476534 & 2.13235 \\
\hline & $5+$ & 1233 & 1237 & 1214 & 1228 & 10.03327796 & 0.817042 \\
\cline { 2 - 8 } & $6+$ & 1403 & 1409 & 1383 & 1398.333 & 11.11555467 & 0.794915 \\
\cline { 2 - 8 } & $7+$ & 1869 & 1871 & 1781 & 1840.333 & 41.96294662 & 2.280182 \\
\cline { 2 - 8 } $\mathrm{MeOH}$ & $8+$ & 1888 & 1913 & 1861 & 1887.333 & 21.23414441 & 1.125087 \\
\hline
\end{tabular}

Table 4. CCS values, average, and standard deviation results calculated for the less extended conformations of ubiquitin $\left(2^{\text {nd }}\right.$ peak $)$ for both native and methanolic conditions.

\begin{tabular}{cccccccc}
\hline $2^{\text {nd }}$ peak & \multicolumn{7}{c}{$\operatorname{CCS}$ VALUES $\left(\AA^{2}\right)$} \\
\hline & Charge States & $1^{\text {st }}$ day & $2^{\text {nd }}$ day & $3^{\text {rd }}$ day & AVERAGE & STD DEVIA & $\% \mathrm{CV}^{*}$ \\
\hline & $5+$ & n/a & n/a & n/a & n/a & n/a & n/a \\
\cline { 2 - 9 } NATIVE & $6+$ & 1416 & 1370 & 1371 & 1385.667 & 21.4527905 & 1.54819 \\
\hline & $5+$ & 1354 & 1355 & 1291 & 1333.333 & 29.9369708 & 2.245273 \\
\cline { 2 - 8 } & $6+$ & 1648 & 1649 & 1732 & 1676.333 & 39.3643945 & 2.348244 \\
\cline { 2 - 8 } & $7+$ & n/a & n/a & 1834 & 1834 & n/a & n/a \\
\cline { 2 - 8 } MeOH & $8+$ & n/a & n/a & n/a & n/a & n/a & n/a \\
\hline
\end{tabular}

Figure 14A and 14B shows ATDs for ubiquitin $5^{+}$and $6^{+}$in aqueous and denaturing conditions. In solution, aqueous conditions of ubiquitin favor the $\mathrm{N}$-state (native state) while the partially unfolded so-called A-state is dominant in solutions containing $40 \%$ of methanol or more. $[124,128,130,157,173,174]$

The ATD profile generated for ions in aqueous conditions (Figure 14A) presented a narrow structural region with similar cross section values $\left({ }^{\mathrm{TW}} \mathrm{CCSN}_{2}-1193 \AA^{2}\right.$ and $1232 \AA^{2}$, for ubiquitin $5^{+}$and $6^{+}$, respectively) corresponding to compact conformations [175]. For aqueous ubiquitin $6^{+}$ a minor peak is present at $\sim 1386 \AA^{2}$, which is likely composed of partially folded states. Previous reports of the $6^{+}$charge state generated from solutions of ubiquitin in aqueous ammonium acetate with ATDs measured by both drift tube and TWIMS instruments also display this feature. [147, 170] The presence of these states is best explained by the increase in Coulombic repulsion from the additional proton bound to the $6^{+}$charge state versus the $5^{+}$, as the $5^{+}$charge state lacks this more extended feature. [121] 
Figure 14B illustrates the ATD profile obtained for ions in denaturing conditions. The distribution for ubiquitin $5^{+}$in denaturing conditions is similar to the one presented by $5^{+}$in native conditions displaying a distribution of compact ions $\left(\sim 1228 \AA^{2}\right)$ with the addition of a distribution extension to higher drift time values that is the region corresponding to partially folded ions $(\sim 1333$ $\left.\AA^{2}\right)$.

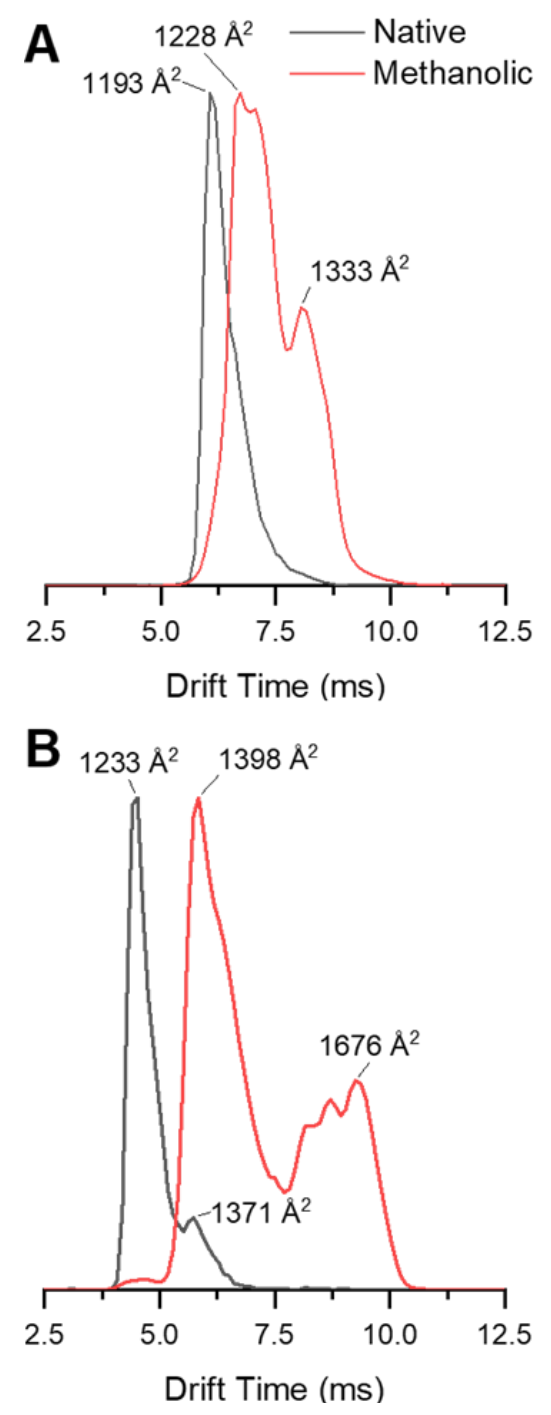

Figure 14. Intensity normalized arrival time distributions (ATDs) of ubiquitin $5^{+} \mathrm{A}$ ) and $6^{+} \mathrm{B}$ ) charge states sprayed from native (black trace) and denaturing (red trace) conditions.

Ubiquitin $6^{+}$in denaturing conditions gives a broad distribution (from $\sim 1300 \AA^{2}$ to 1900 $\AA^{2}$ ) that can be related to multiple stable, elongated forms. Although this distribution is broad, there are 2 features with maxima at $\sim 1398 \AA^{2}$ and $\sim 1676 \AA^{2}$, corresponding to a partially unfolded intermediate state and partially unfolded structure arising from the A state, respectively. 
Figure 15 presents the CCS distributions for all charge states of electrosprayed ubiquitin ions from aqueous and denaturing solutions. The distributions for ubiquitin $7^{+}$and $8^{+}$prepared in denaturing conditions are dominated by relatively sharper features at $\sim 1834 \AA^{2}$ and $\sim 1906 \AA^{2}$, respectively.

Previously published reports applied CCS measurements to access structural transitions of ubiquitin present in three conformations regions denominated as compact region (CCS values ranging from $\sim 950$ to $1250 \AA^{2}$ ), partially folded region (CCS values ranging from $\sim 1250$ to 2050 $\AA^{2}$ ), and elongated region (CCS values ranging from $\sim 2100$ to $2350 \AA^{2}$ ). [170, 176] Comparison of the CCS distributions observed for ubiquitin $7^{+}$and $8^{+}$in this study with the proposed by the literature suggests that for these charge states, the presence of only partially folded and elongated ions populations is noticed. [176]

Sharper features in protein ATDs with CCS values above $\sim 1500 \AA^{2}$ indicate that the ion conformer population is collapsed into relatively few stable structures that exist over a narrow region of the available cross section space and appear as a result of protein unfolding. $[170,176]$ 

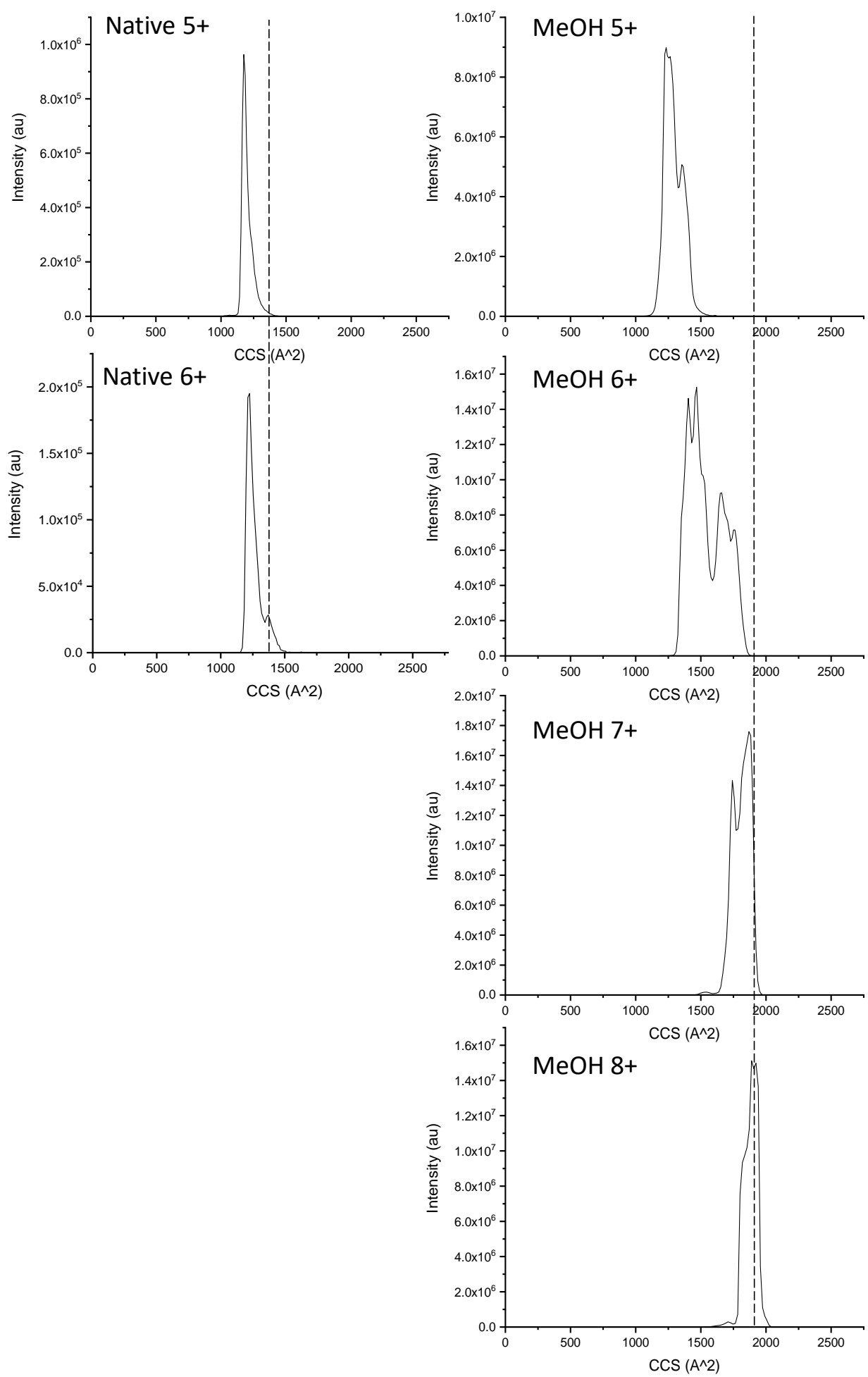

Figure 15. CCS distributions for all charge states of electrosprayed ubiquitin ions from aqueous and denaturing solutions. The dashed lines denote the most elongated conformational state for both conditions. 


\subsection{Characterization of Gaseous Ubiquitin Structures with Ion/Ion Reactions}

\subsubsection{Covalent Modification of Ubiquitin via Ion/Ion Reactions in the Gas Phase}

Structural analysis of proteins via CLMS technique relies on the reactivity and accessibility of the amino acids present in a protein sequence when exposed to a selected label during an ion/ion reaction to generate a protein ligand complex. Gas-phase covalent bond reactions can yield a level of selectivity that is not achieved for solution phase reactions since the proteins can be isolated using a quadrupole mass filter preceding the reaction and the extent of the reaction can be controlled via instrument tunning. [177]

Covalent bond formation occurs via ion/ion reactions by a three-step process: 1) Formation of a stable, long-lived electrostatically bound complex; 2) Activation of the complex; and 3) Dissociation of the leaving group from the complex.

The first step is completed by trapping both reagent anions (sulfobenzoyl-HOAt) and protein cations (ubiquitin) in the trap cell. A minimal amplitude trap traveling wave $(<0.2 \mathrm{~V})$ is used to promote better mixing between protein and reagent and, in effect, increasing the effective reaction time. [178]

The electrostatically product is observed by a shift in $\mathrm{m} / \mathrm{z}$ equal to a reduction in charge by the number of reagents electrostatically attached to the proteins and an increase in mass equal to the molecular mass of the reagent.

Next, the electrostatic complex is activated. The pressures and voltages from the source and into the trap cell were kept identical to the conditions used to measure the CCS values so that the protein ions would not be excessively energized prior to the ion/ion reaction. Thus, the protein ions that were labeled structurally correlate with the observed arrival time distributions (ATDs) and calculated CCS values.

The transition state for a covalent reaction between a model amine and sulfobenzoyl-HOAt has been determined to be $17.4 \mathrm{kcal} / \mathrm{mol}$ higher in energy than the electrostatic product. [146] The sulfonate is expected to be electrostatically attached to a protonated arginine, lysine, or histidine residue. The proton transfer barrier for transfer from guanidinium to sulfonate was calculated to be $61 \mathrm{kcal} / \mathrm{mol}$ and for transfer from ammonium to sulfonate was calculated to be $28 \mathrm{kcal} / \mathrm{mol}$ higher in energy than the complex. Since collisional activation on a mass spectrometry timescale is kinetically controlled, enough collisional energy is applied to form the covalent reaction 
transition state but not high enough to result in proton transfer without covalent bond formation or fragmentation of the protein.

Though the application of this energy may lead to coulombically-driven unfolding of the protein, the strong electrostatic "anchor" holds the reagent in place. The through-bond distance from the reactive carbonyl carbon to the sulfonate oxygens in the reagent is approximately $6.4 \AA$. Thus, the reactive side chain must be close by the charged anchoring residue (i.e., on the surface of the protein) and a reactive nucleophile.

Therefore, though collision-induced unfolding or intramolecular proton transfer may occur during the activation of the complex, these processes are not expected to affect the ability of the ion/ion reaction to report on surface accessible regions of the protein that are nearby external, protonated side chains.

The fact that the reagent to protonated side chain noncovalent bond is not fragmented under these conditions illustrates that the applied activation to form the covalent product is mild. The applied collisional energy will drive off the weakly-bound leaving group after the covalent product is formed. The covalent reaction is observed by a decrease in $\mathrm{m} / \mathrm{z}$ equal to neutral loss of the leaving group.

Ion/ion reactions were used to probe the gas phase microenvironment and relative reactivity of lysine and arginine side chains in ubiquitin cations formed from the aqueous and denaturing solutions. Previously, histidine was found to only react with low energy activation applied over long time periods. [146] These conditions cannot be accessed with the instrument used in this study as CID is performed in transmission mode (beam-type CID). Therefore, we do not expect to observe histidine modification. Ion/ion reactions were performed under similar ion optics voltage conditions as the CCS measurements from the source up to and including the trap cell (vide Table 2).

The choice of the sulfobenzoyl-HOAt reagent (versus, e.g., sulfobenzoyl-Nhydroxysuccinimide) was based on its relatively low activation energy for covalent reactions in the gas phase, its simple and one-pot synthesis, and the ability of sulfo-benzoyl-HOAt to react with amino acids side chains such as arginine and lysine. [146]

Figure 16A displays the ion/ion reaction of ubiquitin $6^{+}$electrosprayed from aqueous conditions and sulfobenzoyl-HOAt. The amide bond formation between ubiquitin and 3sulfobenzoate is characterized by the neutral loss of HOAt (Molecular mass $=135.1235 \mathrm{~g} / \mathrm{mol}$ ) 
from the ion/ion reaction product. The peak $[\mathrm{M}+6 \mathrm{H}+]^{5+}$ represents the electrostatic product formed between ubiquitin $6^{+}$and the reagent, $[\mathrm{M}+5 \mathrm{H}+*]^{5+}$ is covalently modified ubiquitin, and the $[\mathrm{M}+5 \mathrm{H}]^{5+}$ peak is the proton transfer product corresponding to the loss of the electrostatically attached reagent.

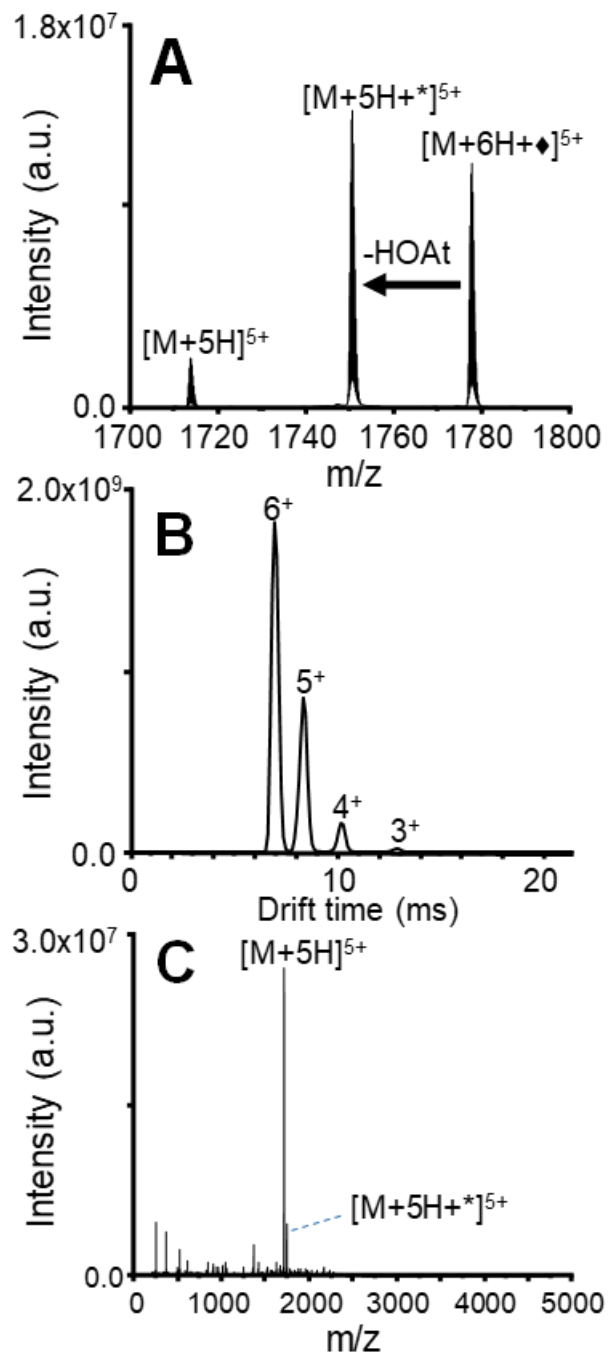

Figure 16. Covalent modification of [ubiquitin $+6 \mathrm{H}]^{6+}$ ionized from native conditions with [sulfo-HOAt] ${ }^{-}$. (A) Product ion spectrum of the ion/ion reaction between [ubiquitin $+6 \mathrm{H}]^{6+}$ and [sulfo-HOAt $-\mathrm{H}$ ] prior to activation. refers to electrostatic attachment of the reagent and * refers to covalent modification. (B) ATD of the full scan (mass range of 100 to $500 \mathrm{~m} / \mathrm{z}$ ) corresponding to ion/ion reactions between [ubiquitin $+6 \mathrm{H}]^{6+}$ and [sulfo-HOAt $-\mathrm{H}]^{-}$revealing the mobility separation of covalently modified products generated with different extents of modification. (C) Mass spectrum resulting from CID of the ion/ion reaction product (corresponding to $72-83 \mathrm{~ms}$ in the ATD). 
In order to favor covalent product formation (as opposed to proton transfer) several parameters were optimized aiming to apply energy below the threshold for proton transfer product formation but above the transition state energy for covalent bond formation. [179] With the helium cell and IM pressures used to measure CCS, the only observed product upon collisional activation was loss of the reagent from the ion/ion product complex. This is due to intentional rapid thermalization of ions by many low-energy collisions as they enter the mobility cell, preventing unintended activation of ions. [35] However, rapid thermalization results in the need to use much higher voltages to achieve ion activation, with the consequence of not being able to access the neutral loss of HOAt channel, as the loss of the entire reagent is kinetically favorable.

Previous work has shown that the transition state for loss of an electrostatically bound reagent is very loose compared the transition state for covalent reaction, [63] restraining the appearance of the covalent reaction to activation energies below the threshold for loss of the entire reagent. Therefore, the gas flows into the helium and IM cells were set to $20 \mathrm{~mL} / \mathrm{min}$ each $(0.59$ and 0.66 mbar pressures for each of the cells. respectively). This way, the injection energy into the mobility cell was able to be reduced (center of mass energy of $3.6 \mathrm{kcal} / \mathrm{mol}$ for $5^{+}$, Table 5) and fewer energizing collisions occur. The equation used to calculate the center-of-mass energy was as it follows:

$$
E_{C O M}=\frac{E_{k} \times M_{g}}{M_{x} \times M_{g}}
$$

where $\mathrm{E}_{\mathrm{COM}}$ is the center-of-mass energy, $\mathrm{E}_{\mathrm{k}}$ is the kinetic energy (in eV) of the sample ion, $\mathrm{M}_{\mathrm{g}}$ is the molecular weight of the collision gas, and $\mathrm{M}_{\mathrm{x}}$ is the monoisotopic mass of the ion. 
Table 5. Center-of-mass energy ( $\mathrm{E}_{\mathrm{COM}}$ ) calculated for each charge state of ubiquitin during the ion/ion reaction process ( $\mathrm{E}_{\mathrm{COM}}$ for reaction).

\begin{tabular}{|c|c|c|}
\hline \multirow[b]{2}{*}{$\begin{array}{c}\text { Ubi charge } \\
\text { state }\end{array}$} & \multicolumn{2}{|c|}{$\mathrm{E}_{\text {COM }}$ for reaction } \\
\hline & $\mathrm{eV}$ & $\mathrm{Kcal} / \mathrm{mol}$ \\
\hline $5^{+}$ & 0.156189 & 3.60 \\
\hline $6^{+}$ & 0.195214 & 4.50 \\
\hline $7^{+}$ & 0.23423 & 5.40 \\
\hline $8^{+}$ & 0.273238 & 6.30 \\
\hline
\end{tabular}

The result is efficient formation of the -HOAt without a dominant channel for loss of the entire reagent. The tune parameters used during ion/ion reactions are presented in Table 2. The trap pressure was kept the same. In this way, the ratio of the covalently modified product to the proton transfer (reagent loss) peak was maximized to yield the mass spectrum in Figure 16A. [152] The ATD in Figure 16B was obtained under these conditions and represents the ion mobility separation of different numbers of sequential ion/ion reactions between ubiquitin $6^{+}$and sulfobenzoyl-HOAt . The peak at $65 \mathrm{~ms}$ is related to the precursor ubiquitin $6^{+}$, the peak at $\sim 78 \mathrm{~ms}$ corresponds to the attachment of one sulfobenzoyl-HOAt, and the peaks at $~ 96$ and $120 \mathrm{~ms}$ corresponds to attachment of two and three sulfobenzoyl-HOAt, respectively. Figure 16C displays the mass spectrum at extracted from drift time $72-83 \mathrm{~ms}$ resulting from CID of the ion/ion reaction covalent modified product.

Figure 17 shows the mass spectra related to the peaks in the ATD which correspond to the ion/ion reactions products obtained for ubiquitin $7^{+}$in denaturing conditions, with up to three covalent additions of sulfobenzoyl-HOAt reagents. Fragments from CID of the labeled protein ions were only investigated for addition of a single label to help prevent label-induced structural changes from affecting our analysis. [67] 


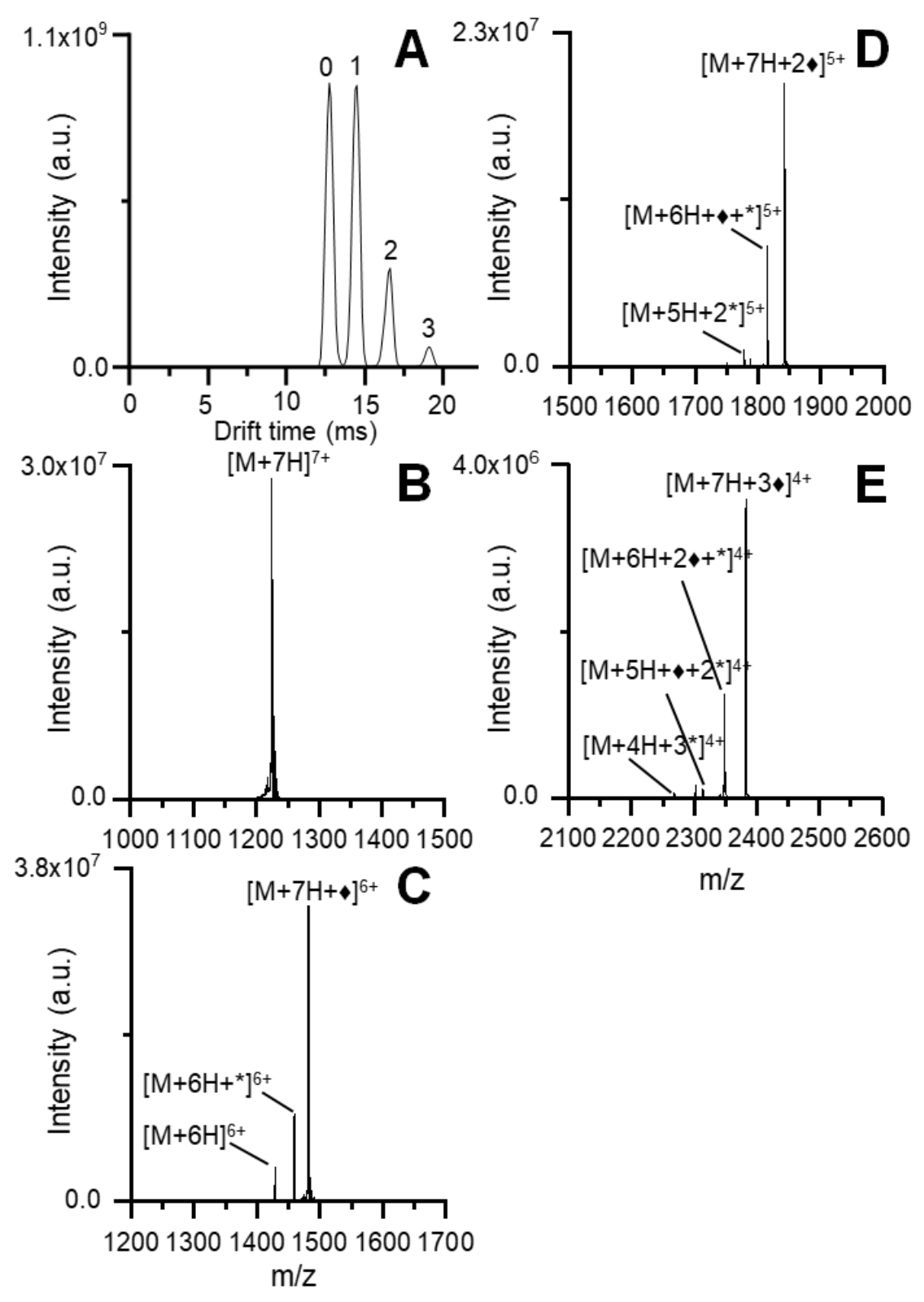

Figure 17. (A) Post-ion/ion reaction IM spectrum and mass spectra from zero (B), one (C), two (D), and three $(\mathbf{E})$ anion attachments. refers to electrostatic attachment of the reagent and $*$ refers to covalent modification.

The charge states $5^{+}$and $6^{+}$ionized from aqueous conditions and $5^{+}, 6^{+}, 7^{+}$, and $8^{+}$all displayed a neutral loss of $\mathrm{m} / \mathrm{z} 136$ (the mass of the leaving group, HOAT) following ion/ion reactions with sulfobenzoyl-HOAt. However, $7^{+}$and $8^{+}$from aqueous conditions and $9^{+}$from denaturing conditions did not show neutral loss of HOAt. The only products were the electrostatic addition of sulfobenzoyl-HOAt and loss of the entire reagent. 
This observation is attributed to the lack of unprotonated lysine or arginine residues available on the exterior of the protein with $7^{+}$and $8^{+}$ionized from aqueous conditions and $9^{+}$ ionized from denaturing conditions. The difference in reactivity between the $7^{+}$and $8^{+}$charge states ionized from aqueous solution and $7^{+}$and $8^{+}$from denaturing solution indicate that their protonation sites and gas-phase structures are likely different. The injection energy was controlled to prevent fragmentation of the protein backbone. No fragments other than the loss of HOAt or the entire reagent were observed without adding collisional energy in the transfer cell.

\subsubsection{Comparison and Characterization of the Ubiquitin Ion Structures Obtained from Aqueous and Denaturing Solutions}

CID was performed upon injection into the transfer cell to form covalent modification sequence fragments originating from different charge states of ubiquitin in both aqueous (ubiquitin $5^{+}$and $6^{+}$) and denaturing (ubiquitin $5^{+}$to $8^{+}$) conditions. Table 6 summarizes the collision energy voltages applied to the transfer cell for each CID experiment.

Table 6. Collision energy voltages applied to the transfer cell for each CID experiment.

\begin{tabular}{ccc}
\hline Samples & Ubiquitin Charge State & Transfer Collision Energy $(\mathbf{V})$ \\
\hline Native & $5^{+}$ & 80 \\
\cline { 2 - 3 } & $6^{+}$ & 55 \\
\hline Methanolic & $5^{+}$ & 75 \\
& $6^{+}$ & 60 \\
\hline & $7^{+}$ & 50 \\
\hline & $8^{+}$ & 25 \\
\hline
\end{tabular}

The covalent product ions generated $b$ (N-terminal) and $y$ (C-terminal) fragment ions that matched drift times of their precursors. Figure 18 shows the fragment mass spectrum resulting from CID of the covalent product $\left[\mathrm{M}+5 \mathrm{H}+*{ }^{*}\right]^{5+}$ in native conditions that was used to determine the sites of covalent modification. The fragment ion annotations from the solution condition and charge state-dependent ion/ion gas-phase covalent modification of ubiquitin are shown in Figures 19 and 20. 

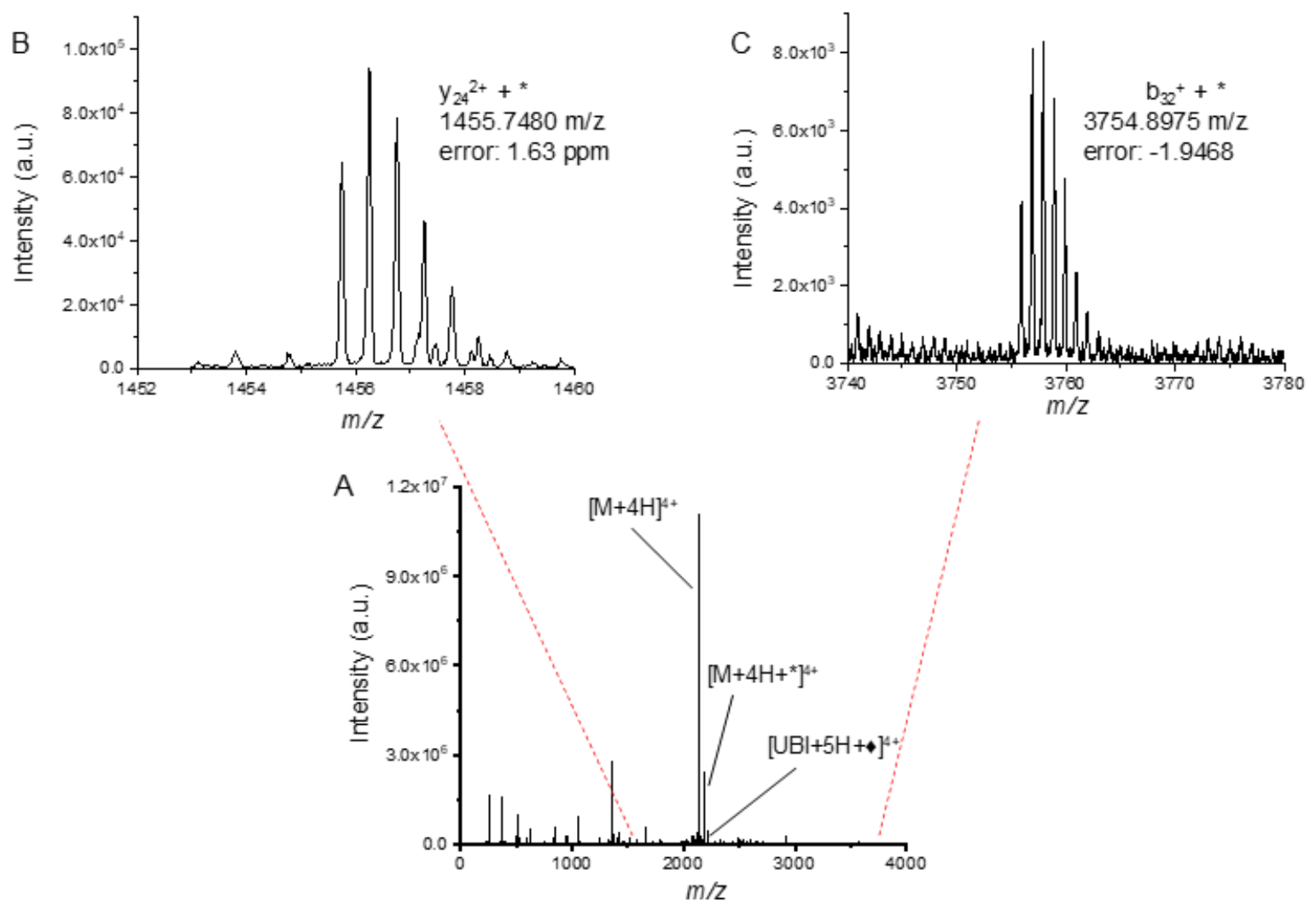

Figure 18. A) MS/MS spectrum of Ubi $5^{+}$in aqueous conditions during ion/ion reactions. B) Ion fragment covalently modified $\mathrm{Y}_{24}{ }^{2+}+*(2909.4864 \mathrm{~m} / \mathrm{z})$ and C) Ion fragment covalently modified $\mathrm{B}_{32}{ }^{+}+*$ $(3754.8975 \mathrm{~m} / \mathrm{z})$. 


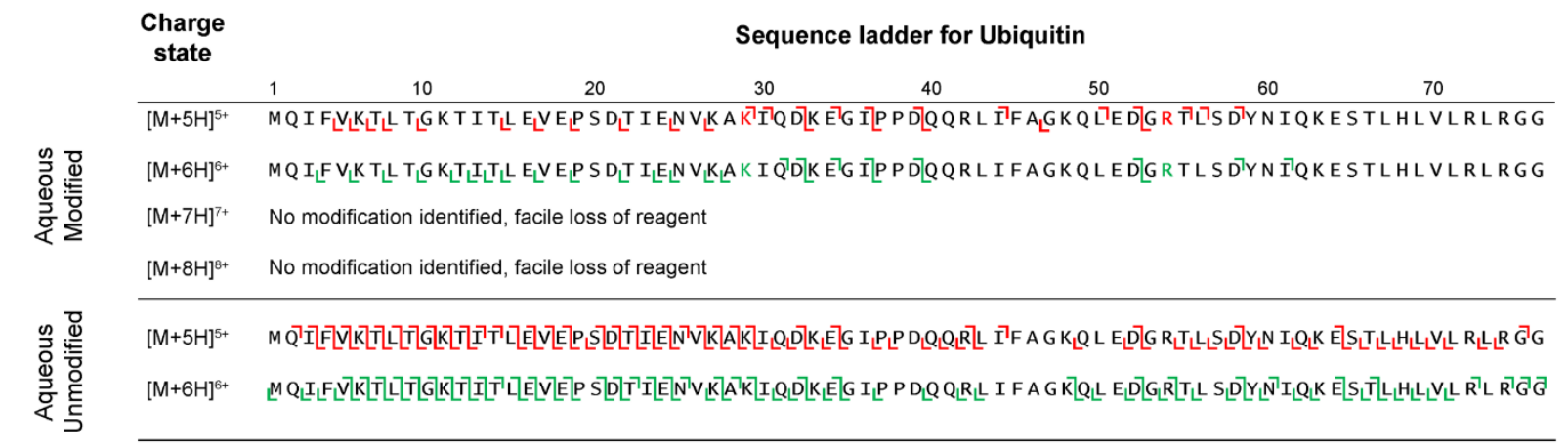

Figure 19. Sequence Ladder for Aqueous Ubiquitin in different charge states displaying the covalently modified fragmentation sites and the modified residues.

For ubiquitin $5^{+}$and $6^{+}$electrosprayed from aqueous conditions the modified fragment ions generated suggested covalent modifications to lysine 29 (modified $b_{29}$ ) and arginine 54 (modified y24) which is in agreement with previously published work. [152]

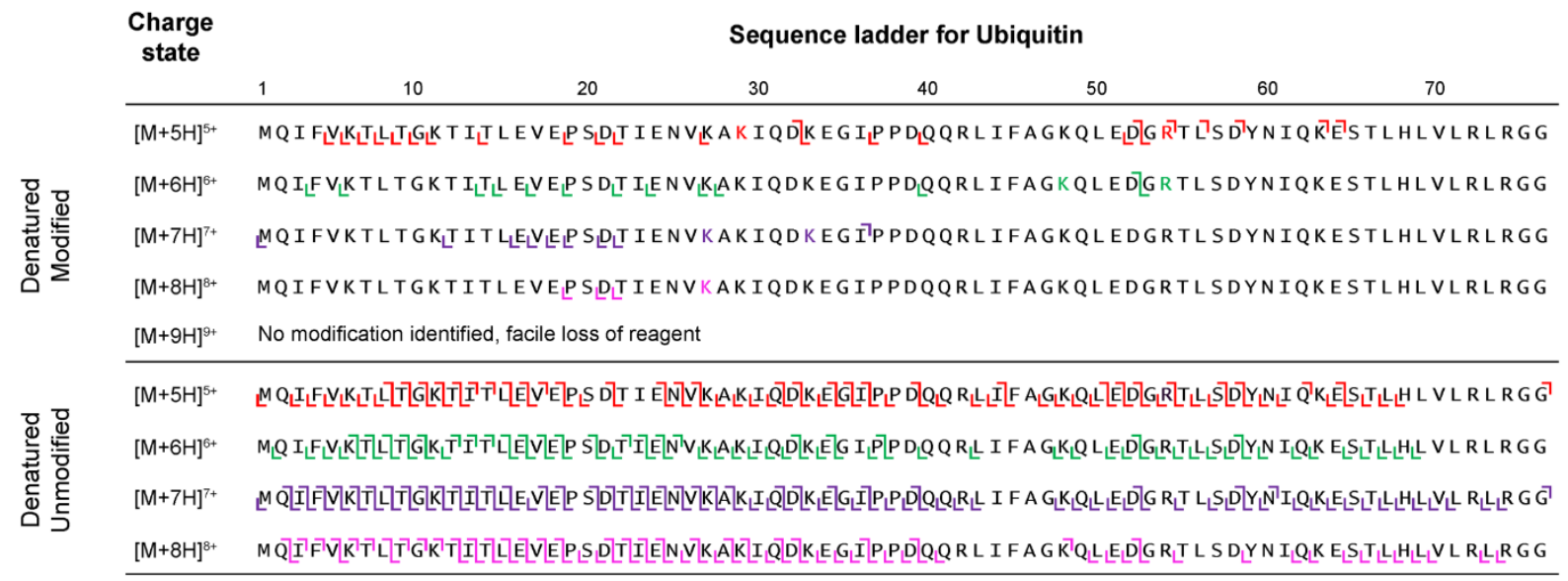

Figure 20. Sequence Ladder for Denatured Ubiquitin in different charge states displaying the covalently modified fragmentation sites and the modified residues.

The residues available for covalent modification must be accessible to the reagent - which excludes side chains buried in the interior of the protein - and reactive towards the reagent, precluding protonated and non-nucleophilic sites. Modification sites were annotated based on the smallest terminal (b- or y-ion) fragment that has a $\mathrm{m} / \mathrm{z}$ shift corresponding to covalent addition. The process of assigning labeled sites is as follows: b- and y-ions that matched the $\mathrm{m} / \mathrm{z}$ of sequence 
fragments plus the mass of the covalent label were annotated as covalently labeled fragments and manually validated.

Next, the mass spectra were manually compared against spectra resulting from CID of unmodified ubiquitin at the same charge. Fragments that were originally annotated as covalently labeled that matched the $\mathrm{m} / \mathrm{z}$ and isotopic distribution of fragments resulting from CID of unmodified ubiquitin were thrown out and considered false positives. Side chains were assigned as covalently labeled only if there was no evidence for covalent labeling of amino acid residues $\mathrm{N}$-terminal (for b-ions) or C-terminal (for $\mathrm{y}$-ions) to the assigned site (i.e., no labeled sequence fragments that include these residues).

For example, Figure 19 shows that the smallest labeled b-ion was modified $b_{29}$, but unmodified fragments are observed for $\mathrm{b}_{27}$ and $\mathrm{b}_{28}$, ions that include the $\mathrm{N}$-terminus, $\mathrm{K} 6$, $\mathrm{K} 11$, and K27, but not K29. Therefore, there is no evidence for labeling of any of these amino acids, but the observation of b-ions matching the mass of the addition of the covalent label that include K29 suggests that K29 is the labeled side chain.

These results correlate to the crystal structure of ubiquitin (PDB 1UBQ) [122] where the suggested modified residues are exposed and accessible to the reagent (Figure 21). Recently, results from $193 \mathrm{~nm}$ ultraviolet photodissociation (UVPD) were used to determine the protonation sites for different native charge states of ubiquitin in the gas phase. [180]

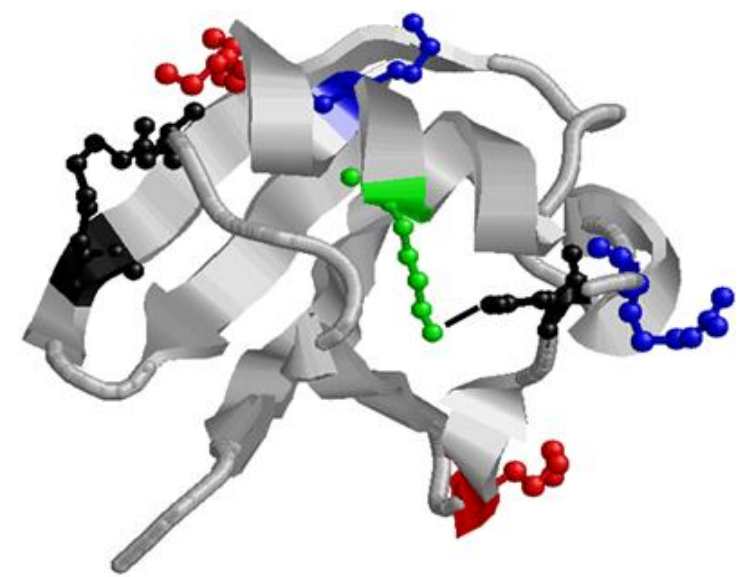

Figure 21. X-ray structure of ubiquitin (1ubq). The blue residues (K29, R54) are labeled under native conditions and the red (K33, K48) and green residue (K27) are labeled only under denaturing conditions. The red residues are protonated under native conditions and the green residue is buried and participates in a salt bridge with D52 (black). K11 is black as it participates in a salt bridge but in not labeled under any conditions. The black line between K27 and D52 represents the salt bridge. 
The possible protonation sites for the $5^{+}$and $6^{+}$charge state were determined to be Q2, P19, K33, R42, K48, K63, and R74. For both charge states, K29 and R54 are not protonated, rendering them reactive to sulfobenzoyl-HOAt. The solvent-accessible surface area (SASA) was calculated from the crystal structure with a probe size of $1.4 \AA$ (i.e., the van der Waals radius of water) with the GETAREA program. [181] Side chains with a SASA ratio above $30 \%$ were considered solvent accessible. [182] Including the accessible arginine and lysine side chains from the SASA calculation and excluding the UVPD-determined protonated side chains limits the remaining available sites for labeling by sulfobenzoyl-HOAt to K6, K11, K29, R54, and R72, although K11 (and K27) participates in a salt bridge and thus may not be labeled if these salt bridges are not disrupted under our labeling conditions. [183]

The observed labeling of K29 and K54 (Figure 19) suggests that ubiquitin structures electrosprayed from aqueous conditions retain elements of solution structure, as predicted by molecular dynamics [184] and the structure relaxation approximation [184, 185].

$\mathrm{K} 27$ is not labeled, although it is only two residues away from K29, and is also not protonated. This may be evidence that elements of solution structure can be maintained, as K27 and K29 are in an alpha helix. Although the side chain of K27 faces the interior of the protein, the alpha helix positions K29 oriented outwards. [122]

Another interpretation of these results could suggest that the label is electrostatically bound to a side chain that is greater than $6.4 \AA$ from the primary amine of the K27 side chain. Nonetheless, the labeling of K29 and K27 is not random (it occurs repeatably for both $5^{+}$and $6^{+}$charge states electrosprayed from aqueous solution) and does correlate with the region of the protein including K29 being accessible.

The combination of CCS data, mass spectra, identified covalently modified residues, and modeling for native ubiquitin $5^{+}$and $6^{+}$suggest that ubiquitin structures remain compact in the gas phase when electrosprayed from aqueous conditions. [184]

Ubiquitin has been shown to undergo an alcohol-induced transition to a partially folded state (A state). For the A state, NMR experiments performed in a 40:60 water:methanol solution suggested that it retains a majority of its native secondary structural elements in the N-terminal half, whereas the structure of the C-terminal half unfolds to a highly helical more elongated state. [121, 186-188] 
For the $5^{+}$ion sprayed from a denaturing solution, our ion/ion reaction results show that K29 and R54 are labeled (Figure 19), the same results as determined for the $5^{+}$ions from aqueous conditions, consistent with CCS distribution being very similar between the $5^{+}$sprayed from denaturing conditions and the $5^{+}$and $6^{+}$sprayed from native conditions. The ion/ion covalent labeling also illustrates that the peak around $1400 \AA$ in the aqueous $6^{+}$and denaturing $5^{+}$likely reflect compact structures, since the labeled sites are identical for native $5^{+} / 6^{+}$and denaturing $5^{+}$.

This is consistent with molecular dynamics data that show reversible unfolding and folding for ubiquitin $6^{+}$ions generated from native conditions for $1 \mu \mathrm{s}$ in the gas phase. [184] Additionally, the $6^{+}$and $7^{+}$charge state fragments include modified $y_{24}$, also indicating that R54 was labeled. The labeling of R54 under various conditions indicates that for charge states $5^{+}-7^{+}$, R54 is unprotonated, accessible, and sufficiently reactive under all these conditions.

However, the $6^{+}, 7^{+}$, and $8^{+}$charge states of ubiquitin sprayed from denaturing solution were all labeled at different lysine residues, with no evidence for labeling at the K29 residue. As previously illustrated, these ions all produced ATDs showing more extended conformations. This suggests that K29 is no longer the most reactive accessible lysine side chain for these charge states.

The $6^{+}$fragmentation data shows that K48 is likely labeled (modified $\mathrm{b}_{52}$ ), the $7^{+}$ fragmentation data shows labeling likely occurs on $\mathrm{K} 33$ (modified $\mathrm{b}_{36}$ ), and the $8^{+}$data may provide evidence for the labeling of K27, though the lack of labeled b-ions gives some ambiguity to this assignment. The reduced number of labeled sequence fragments for the $8^{+}$ions is likely a consequence of most of the reactive residues in ubiquitin being protonated, diminishing the overall reactivity and the number of available sites for labeling.

The labeling of $6^{+} \mathrm{K} 48$ and $7^{+}$at $\mathrm{K} 33$ is likely due to changes in preferred protonation sites following the unfolding of the protein, as are K33 and K48 can both be protonated when sprayed from aqueous conditions. NMR measurements have demonstrated that a characteristic of the Astate is that the solution salt bridge between $\mathrm{K} 27$ and D52, which stabilizes the fold of the protein and buries K27 in the interior of the protein, is disrupted. [187, 188]

Therefore, our results for $6^{+}$and $7^{+}$ionized from denaturing conditions correlate with at least partially disrupted solution states. Thus, covalent labeling by ion/ion reactions is expected to be a powerful tool for protein structural analysis. 


\section{CONCLUSION}

Ubiquitin ions electrosprayed from aqueous and denaturing solutions have been analyzed by IM-MS/MS and covalent structural probes delivered by ion/ion reactions inside of the mass spectrometer. Ubiquitin conformational populations were evaluated prior to performing ion/ion reactions by IM-MS, ensuring that energy imparted on the ions between the source and trap cell did not lead to collision induced unfolding.

Examination of the conformation types as function of the solution conditions and charge states allowed for solution structures to be correlated to gas-phase measurements, suggesting the preservation of solution-like structures in the gas phase. Ions generated from aqueous solution had CCS values corresponding to compact conformations while ubiquitin $6^{+}$also exhibited a minor peak at $\sim 1371 \AA^{2}$, which has been attributed to partially folded states due to the increase in Coulombic repulsion over the $5^{+}$charge state.

On the other hand, arrival time distributions for ubiquitin in denaturing conditions presented much higher CCS values which have been previously correlated to multiple elongated stable conformations. [167, 168, 172]

The covalent modification data revealed distinct characteristics for ions originating from either aqueous or denaturing conditions. For aqueous conditions, the modified fragment ions suggested covalent modifications to lysine 29 (modified $b_{32}$ ) and arginine 54 (modified $\mathrm{y}_{24}$ ). It is possible that elements of secondary structure as well as tertiary structure are conserved explained by the covalent modification of K29 instead of the buried and salt bridged K27. [63, 178]

These results correlate to the crystal structure of ubiquitin (PDB 1UBQ) [122], molecular dynamics results, [181] and UVPD data, [82] where the modified residues are exposed and accessible to the reagent. Ion/ion reaction results for ubiquitin $5^{+}$sprayed from denaturing solutions also reveal the labeling of K29 and R54, agreeing with the CCS data, and suggesting that aqueous $6^{+}$and denaturing $5^{+}$are structurally very similar.

Therefore, the denaturing $5^{+}$ion is produced from the remaining compact ubiquitin population in denaturing solutions. The $6^{+}, 7^{+}$, and $8^{+}$charge states of ubiquitin sprayed from denaturing solutions were labeled at various lysines, accessible most likely due to the changes in possible protonation sites as a result disruption of the salt bridge between K27 and D52 after methanol-induced unfolding. [103, 180] 
Overall, the analysis of protein structures by covalent modification in the gas phase analyzed by IM-MS/MS suggests that the gas phase is a suitable environment for probing protein structure if care is taken to ensure gentle ion introduction. 


\section{REFERENCES}

1. Ishima, R. and D.A. Torchia, Protein dynamics from NMR. Nat Struct Biol, 2000. 7(9): p. 740-3.

2. Alberts, B., The cell as a collection overview of protein machines: Preparing the next generation of molecular biologists. cell, 1998. 92: p. 291-294.

3. Sanger, F., The terminal peptides of insulin. Biochemical Journal, 1949. 45(5): p. 563.

4. de Chadarevian, S., Protein sequencing and the making of molecular genetics. Trends in biochemical sciences, 1999. 24(5): p. 203-206.

5. Edman, P., Mechanism of the Phenyl Iso thiocyanate Degradation of Peptides. Nature, 1956. 177(4510): p. 667-668.

6. $\quad$ Smith, J.B., Peptide sequencing by Edman degradation. e LS, 2001.

7. Edman, P. and G. Begg, A protein sequenator, in European Journal of Biochemistry. 1967, Springer. p. 80-91.

8. Geballe, T.R. and L.J.A. Tielens, Protein Ladder Sequencing Brian T. Chait, Rong Wang, Ronald C. Beavis. SCIENCE, 1993. 262: p. 1.

9. Kaur, H., et al., Analytical techniques for characterization of biological molecules proteins and aptamers/oligonucleotides. Bioanalysis, 2018. 11(2): p. 103-117.

10. Kaur, H., et al., Analytical techniques for characterization of biological moleculesproteins and aptamers/oligonucleotides. Bioanalysis, 2019. 11(02): p. 103-117.

11. Aebersold, R. and D.R. Goodlett, Mass spectrometry in proteomics. Chemical reviews, 2001. 101(2): p. 269-296.

12. Domon, B. and R. Aebersold, Mass spectrometry and protein analysis. science, 2006. 312(5771): p. 212-217.

13. De Hoffmann, E. and V. Stroobant, Mass spectrometry: principles and applications. 2007: John Wiley \& Sons.

14. Loo, J.A., Loo, R. R. O., Udseth, H. R., Edmonds, C. G., Smith, R. D., Solvent-Induced Conformational-Changes of Polypeptides Probed by Electrospray-Ionization MassSpectrometry. Rapid Communications in Mass Spectrometry, 1991. 5(3): p. 101-105.

15. Chowdhury, S.K., V. Katta, and B.T. Chait, An electrospray-ionization mass spectrometer with new features. Rapid Commun Mass Spectrom, 1990. 4(3): p. 81-7.

16. Cech, N.B. and C.G. Enke, Practical implications of some recent studies in electrospray ionization fundamentals. Mass spectrometry reviews, 2001. 20(6): p. 362-387.

17. Kebarle, P. and U.H. Verkerk, Electrospray: from ions in solution to ions in the gas phase, what we know now. Mass spectrometry reviews, 2009. 28(6): p. 898-917. 
18. Breuker, K. and F.W. McLafferty, Stepwise evolution of protein native structure with electrospray into the gas phase, 10- 12 to $102 \mathrm{~s}$. Proceedings of the National Academy of Sciences, 2008. 105(47): p. 18145-18152.

19. De La Mora, J.F., Electrospray ionization of large multiply charged species proceeds via Dole's charged residue mechanism. Analytica chimica acta, 2000. 406(1): p. 93-104.

20. Wilm, M. and M. Mann, Analytical properties of the nanoelectrospray ion source. Analytical chemistry, 1996. 68(1): p. 1-8.

21. Wilm, M.S. and M. Mann, Electrospray and Taylor-Cone theory, Dole's beam of macromolecules at last? International Journal of Mass Spectrometry and Ion Processes, 1994. 136(2-3): p. 167-180.

22. Heck, A.J.R., Native mass spectrometry: a bridge between interactomics and structural biology. Nature methods, 2008. 5(11): p. 927-933.

23. Ishii, K., M. Zhou, and S. Uchiyama, Native mass spectrometry for understanding dynamic protein complex. Biochim Biophys Acta Gen Subj, 2018. 1862(2): p. 275-286.

24. Lanucara, F., et al., The power of ion mobility-mass spectrometry for structural characterization and the study of conformational dynamics. Nature Chemistry, 2014. 6(4): p. 281-294.

25. Resing, K.A. and N.G. Ahn, Proteomics strategies for protein identification. FEBS Letters, 2005. 579(4): p. 885-889.

26. Konijnenberg, A., A. Butterer, and F. Sobott, Native ion mobility-mass spectrometry and related methods in structural biology. Biochimica et Biophysica Acta (BBA) - Proteins and Proteomics, 2013. 1834(6): p. 1239-1256.

27. Boeri Erba, E. and $\mathrm{C}$. Petosa, The emerging role of native mass spectrometry in characterizing the structure and dynamics of macromolecular complexes. Protein Science, 2015. 24(8): p. 1176-1192.

28. Clemmer, D.E. and M.F. Jarrold, Ion mobility measurements and their applications to clusters and biomolecules. Journal of mass spectrometry, 1997. 32(6): p. 577-592.

29. Hudgins, R.R., M.A. Ratner, and M.F. Jarrold, Design of helices that are stable in vacuo. Journal of the American Chemical Society, 1998. 120(49): p. 12974-12975.

30. Pringle, S.D., et al., An investigation of the mobility separation of some peptide and protein ions using a new hybrid quadrupole/travelling wave IMS/oa-ToF instrument. International Journal of Mass Spectrometry, 2007. 261(1): p. 1-12.

31. Mason, E.A. and E.W. McDaniel, Transport properties of ions in gases. NASA STI/Recon Technical Report a, 1988. 89: p. 15174.

32. Ruotolo Brandon, T., et al., Evidence for Macromolecular Protein Rings in the Absence of Bulk Water. Science, 2005. 310(5754): p. 1658-1661.

33. Uetrecht, C., et al., Ion mobility mass spectrometry of proteins and protein assemblies. Chemical Society Reviews, 2010. 39(5): p. 1633-1655.

34. Giles, K., et al., Applications of a travelling wave-based radio-frequency-only stacked ring ion guide. Rapid Communications in Mass Spectrometry, 2004. 18(20): p. 2401-2414. 
35. Giles, K., J.P. Williams, and I. Campuzano, Enhancements in travelling wave ion mobility resolution. Rapid Communications in Mass Spectrometry, 2011. 25(11): p. 1559-1566.

36. Giles, K., et al., Applications of a travelling wave-based radio-frequency-only stacked ring ion guide. Rapid Communications in Mass Spectrometry, 2004. 18(20): p. 2401-2414.

37. Ruotolo, B.T. and C.V. Robinson, Aspects of native proteins are retained in vacuum. Current Opinion in Chemical Biology, 2006. 10(5): p. 402-408.

38. Loo, R.R.O., H.R. Udseth, and R.D. Smith, Evidence of charge inversion in the reaction of singly charged anions with multiply charged macroions. The Journal of Physical Chemistry, 1991. 95(17): p. 6412-6415.

39. Ogorzalek Loo, R.R., H.R. Udseth, and R.D. Smith, A new approach for the study of gasphase ion-ion reactions using electrospray ionization. Journal of the American Society for Mass Spectrometry, 1992. 3(7): p. 695-705.

40. Herron, W.J., D.E. Goeringer, and S.A. McLuckey, Product Ion Charge State Determination via Ion/Ion Proton Transfer Reactions. Analytical Chemistry, 1996. 68(2): p. 257-262.

41. Stephenson, J.L. and S.A. McLuckey, Simplification of Product Ion Spectra Derived from Multiply Charged Parent Ions via Ion/Ion Chemistry. Analytical Chemistry, 1998. 70(17): p. 3533-3544.

42. Reid, G.E. and S.A. McLuckey, 'Top down'protein characterization via tandem mass spectrometry. Journal of mass spectrometry, 2002. 37(7): p. 663-675.

43. Webb, I.K., L.J. Morrison, and J. Brown, Dueling electrospray implemented on a travelingwave ion mobility/time-of-flight mass spectrometer: Towards a gas-phase workbench for structural biology. International Journal of Mass Spectrometry, 2019. 444: p. 116177.

44. Ruotolo, B.T., et al., Evidence for Macromolecular Protein Rings in the Absence of Bulk Water. Science, 2005. 310(5754): p. 1658.

45. Skinner, O.S., F.W. McLafferty, and K.J.J.o.t.A.S.f.M.S. Breuker, How ubiquitin unfolds after transfer into the gas phase. 2012. 23(6): p. 1011-1014.

46. Loo, J.A., J.X. He, and W.L.J.J.o.t.A.C.S. Cody, Higher order structure in the gas phase reflects solution structure. 1998. 120(18): p. 4542-4543.

47. Wyttenbach, T. and M.T. Bowers, Structural stability from solution to the gas phase: native solution structure of ubiquitin survives analysis in a solvent-free ion mobility-mass spectrometry environment. The journal of physical chemistry B, 2011. 115(42): p. 1226612275.

48. Katta, V., B.T. Chait, and S. Carr, Conformational changes in proteins probed by hydrogen-exchange electrospray-ionization mass spectrometry. Rapid Communications in Mass Spectrometry, 1991. 5(4): p. 214-217.

49. Engen, J.R. and D.L. Smith, Investigating protein structure and dynamics by hydrogen exchange MS. Analytical Chemistry (Washington, DC), 2001. 73(9): p. 256A-265A.

50. Kaltashov, I.A. and S.J. Eyles, Studies of biomolecular conformations and conformational dynamics by mass spectrometry. Mass spectrometry reviews, 2002. 21(1): p. 37-71. 
51. Wales, T.E. and J.R. Engen, Hydrogen exchange mass spectrometry for the analysis of protein dynamics. Mass spectrometry reviews, 2006. 25(1): p. 158-170.

52. Konermann, L., J. Pan, and Y.-H. Liu, Hydrogen exchange mass spectrometry for studying protein structure and dynamics. Chemical Society Reviews, 2011. 40(3): p. 1224-1234.

53. Wei, H., et al., Hydrogen/deuterium exchange mass spectrometry for probing higher order structure of protein therapeutics: methodology and applications. Drug discovery today, 2014. 19(1): p. 95-102.

54. Pirrone, G.F., R.E. Iacob, and J.R. Engen, Applications of hydrogen/deuterium exchange MS from 2012 to 2014. Analytical chemistry, 2015. 87(1): p. 99-118.

55. $\mathrm{Yu}, \mathrm{C}$. and L. Huang, Cross-linking mass spectrometry (XL-MS): An emerging technology for interactomics and structural biology. Analytical chemistry, 2018. 90(1): p. 144.

56. Holding, A.N., XL-MS: Protein cross-linking coupled with mass spectrometry. Methods, 2015. 89: p. 54-63.

57. Sinz, A., Chemical cross-linking and mass spectrometry to map three-dimensional protein structures and protein-protein interactions. Mass spectrometry reviews, 2006. 25(4): p. 663-682.

58. Shannon, D.A. and E. Weerapana, Covalent protein modification: the current landscape of residue-specific electrophiles. Current opinion in chemical biology, 2015. 24: p. 18-26.

59. Wang, L. and M.R. Chance, Structural mass spectrometry of proteins using hydroxyl radical based protein footprinting. 2011, ACS Publications.

60. Konermann, L., et al., Mass spectrometry combined with oxidative labeling for exploring protein structure and folding. Mass spectrometry reviews, 2010. 29(4): p. 651-667.

61. Kiselar, J.G. and M.R. Chance, Future directions of structural mass spectrometry using hydroxyl radical footprinting. Journal of mass spectrometry, 2010. 45(12): p. 1373-1382.

62. Han, H. and S.A. McLuckey, Selective covalent bond formation in polypeptide ions via gas-phase ion/ion reaction chemistry. Journal of the American Chemical Society, 2009. 131(36): p. 12884-12885.

63. Bu, J., et al., Selective covalent chemistry via gas-phase ion/ion reactions: an exploration of the energy surfaces associated with $N$-hydroxysuccinimide ester reagents and primary amines and guanidine groups. Journal of The American Society for Mass Spectrometry, 2016. 27(6): p. 1089-1098.

64. Mendoza, V.L. and R.W. Vachet, Probing protein structure by amino acid-specific covalent labeling and mass spectrometry. Mass spectrometry reviews, 2009. 28(5): p. 785815.

65. Oetjen, J., S. Rexroth, and B. Reinhold-Hurek, Mass spectrometric characterization of the covalent modification of the nitrogenase Fe-protein in Azoarcus sp. BH72. The FEBS Journal, 2009. 276(13): p. 3618-3627.

66. Guan, J.-Q. and M.R. Chance, Structural proteomics of macromolecular assemblies using oxidative footprinting and mass spectrometry. Trends in Biochemical Sciences, 2005. 30(10): p. 583-592. 
67. Mendoza, V.L. and R.W. Vachet, Probing protein structure by amino acid-specific covalent labeling and mass spectrometry. Mass Spectrometry Reviews, 2009. 28(5): p. 785-815.

68. Peng, Z. and S.A. McLuckey, C-terminal peptide extension via gas-phase ion/ion reactions. International Journal of Mass Spectrometry, 2015. 391: p. 17-23.

69. McGee, W.M. and S.A. McLuckey, Efficient and directed peptide bond formation in the gas phase via ion/ion reactions. Proceedings of the National Academy of Sciences, 2014. 111(4): p. 1288.

70. Prentice, B.M., et al., Strategies for the gas phase modification of cationized arginine via ion/ion reactions. International Journal of Mass Spectrometry, 2013. 354-355: p. 211-218.

71. Mentinova, M. and S.A. McLuckey, Covalent Modification of Gaseous Peptide Ions with $\mathrm{N}$-Hydroxysuccinimide Ester Reagent Ions. Journal of the American Chemical Society, 2010. 132(51): p. 18248-18257.

72. Prentice, B.M. and S.A. McLuckey, Gas-phase ion/ion reactions of peptides and proteins: acid/base, redox, and covalent chemistries. Chemical Communications, 2013. 49(10): p. 947-965.

73. Knock, S.L., et al., N-acylation of Aplysia egg-laying hormone with biotin. Characterization of bioactive and inactive derivatives. Journal of Biological Chemistry, 1991. 266(36): p. 24413-24419.

74. Novak, P., et al., A top-down method for the determination of residue-specific solvent accessibility in proteins. Journal of mass spectrometry, 2004. 39(3): p. 322-328.

75. Prentice, B.M., et al., Gas-phase reactivity of carboxylic acid functional groups with carbodiimides. Journal of the American Society for Mass Spectrometry, 2012. 24(1): p. 30-37.

76. Loo, J.A., et al., Elucidation of Covalent Modifications and Noncovalent Associations in Proteins by Electrospray Ionization Mass Spectrometry, in Techniques in Protein Chemistry IV, R.H. Angeletti, Editor. 1993, Academic Press. p. 23-31.

77. Limpikirati, P., X. Pan, and R.W. Vachet, Covalent Labeling with Diethylpyrocarbonate: Sensitive to the Residue Microenvironment, Providing Improved Analysis of Protein Higher Order Structure by Mass Spectrometry. Analytical Chemistry, 2019. 91(13): p. 8516-8523.

78. Foreman, D.J. and S.A. McLuckey, Recent Developments in Gas-Phase Ion/Ion Reactions for Analytical Mass Spectrometry. Analytical Chemistry, 2019.

79. Limpikirati, P., T. Liu, and R.W. Vachet, Covalent labeling-mass spectrometry with nonspecific reagents for studying protein structure and interactions. Methods, 2018. 144: p. 79-93.

80. Webb, I.K., et al., Gas-phase intramolecular protein crosslinking via ion/ion reactions: ubiquitin and a homobifunctional sulfo-NHS ester. J Am Soc Mass Spectrom, 2013. 24(5): p. 733-43. 
81. Pitts-McCoy, A.M., C.P. Harrilal, and S.A. McLuckey, Gas-Phase Ion/Ion Chemistry as a Probe for the Presence of Carboxylate Groups in Polypeptide Cations. Journal of the American Society for Mass Spectrometry, 2019. 30(2): p. 329-338.

82. Wilkinson, K.D. and A.N. Mayer, Alcohol-induced conformational changes of ubiquitin. Archives of biochemistry and biophysics, 1986. 250(2): p. 390-399.

83. Cox, J.P.L., et al., Dissecting the structure of a partially folded protein: circular dichroism and nuclear magnetic resonance studies of peptides from ubiquitin. Journal of molecular biology, 1993. 234(2): p. 483-492.

84. Briggs, M.S. and H. Roder, Early hydrogen-bonding events in the folding reaction of ubiquitin. Proceedings of the National Academy of Sciences, 1992. 89(6): p. 2017-2021.

85. Pan, Y. and M.S.J.B. Briggs, Hydrogen exchange in native and alcohol forms of ubiquitin. 1992. 31(46): p. 11405-11412.

86. Pan, Y. and M.S. Briggs, Hydrogen exchange in native and alcohol forms of ubiquitin. Biochemistry, 1992. 31(46): p. 11405-11412.

87. Nucci, N.V., M.S. Pometun, and A.J. Wand, Mapping the hydration dynamics of ubiquitin. Journal of the American Chemical Society, 2011. 133(32): p. 12326-12329.

88. Harding, M.M., D.H. Williams, and D.N. Woolfson, Characterization of a partially denatured state of a protein by two-dimensional NMR: reduction of the hydrophobic interactions in ubiquitin. Biochemistry, 1991. 30(12): p. 3120-3128.

89. Stockman, B.J., A. Euvrard, and T.A. Scahill, Heteronuclear three-dimensional NMR spectroscopy of a partially denatured protein: the A-state of human ubiquitin. Journal of biomolecular NMR, 1993. 3(3): p. 285-296.

90. Brutscher, B., R. Brüschweiler, and R.R. Ernst, Backbone dynamics and structural characterization of the partially folded A state of ubiquitin by $1 \mathrm{H}, 13 \mathrm{C}$, and $15 \mathrm{~N}$ nuclear magnetic resonance spectroscopy. Biochemistry, 1997. 36(42): p. 13043-13053.

91. Di Stefano, D.L. and A.J. Wand, Two-dimensional proton nmr study of human ubiquitin: a main chain directed assignment and structure analysis. Biochemistry, 1987. 26(23): p. 7272-7281.

92. Jourdan, M. and M.S. Searle, Insights into the stability of native and partially folded states of ubiquitin: effects of cosolvents and denaturants on the thermodynamics of protein folding. Biochemistry, 2001. 40(34): p. 10317-10325.

93. Makhatadze, G.I., et al., Anion binding to the ubiquitin molecule. Protein science, 1998. 7(3): p. 689-697.

94. Ibarra-Molero, B., G.I. Makhatadze, and J.M. Sanchez-Ruiz, Cold denaturation of ubiquitin. Biochimica et Biophysica Acta (BBA)-Protein Structure and Molecular Enzymology, 1999. 1429(2): p. 384-390.

95. Alonso, D.O.V. and V. Daggett, Molecular dynamics simulations of protein unfolding and limited refolding: characterization of partially unfolded states of ubiquitin in $60 \%$ methanol and in water. Journal of molecular biology, 1995. 247(3): p. 501-520. 
96. Prompers, J.J., C. Scheurer, and R. Brüschweiler, Characterization of NMR relaxationactive motions of a partially folded A-state analogue of ubiquitin. Journal of molecular biology, 2001. 305(5): p. 1085-1097.

97. Segev, E., et al., Conformational evolution of ubiquitin ions in electrospray mass spectrometry: molecular dynamics simulations at gradually increasing temperatures. Physical Chemistry Chemical Physics, 2008. 10(21): p. 3077-3082.

98. Fox, T. and P.A. Kollman, The application of different solvation and electrostatic models in molecular dynamics simulations of ubiquitin: How well is the $x$-ray structure "maintained”? Proteins: Structure, Function, and Bioinformatics, 1996. 25(3): p. 315-334.

99. Marianayagam, N.J. and S.E. Jackson, The folding pathway of ubiquitin from all-atom molecular dynamics simulations. Biophysical chemistry, 2004. 111(2): p. 159-171.

100. Cordier, F. and S. Grzesiek, Quantitative Comparison of the Hydrogen Bond Network of A-State and Native Ubiquitin by Hydrogen Bond Scalar Couplings. Biochemistry, 2004. 43(35): p. 11295-11301.

101. Bagno, A., Quantum Chemical Modeling of Through-Hydrogen Bond Spin-Spin Coupling in Amides and Ubiquitin. Chemistry-A European Journal, 2000. 6(16): p. 2925-2930.

102. Schneider, G.F., et al., Pathway for unfolding of ubiquitin in sodium dodecyl sulfate, studied by capillary electrophoresis. Journal of the American Chemical Society, 2008. 130(51): p. 17384-17393.

103. Vijay-Kumar, S., C.E. Bugg, and W.J. Cook, Structure of ubiquitin refined at 1.8 Aresolution. Journal of molecular biology, 1987. 194(3): p. 531-544.

104. Cornilescu, G., et al., Validation of protein structure from anisotropic carbonyl chemical shifts in a dilute liquid crystalline phase. Journal of the American Chemical Society, 1998. 120(27): p. 6836-6837.

105. Cox, M.J., R. Shapira, and K.D. Wilkinson, Tryptic peptide mapping of ubiquitin and derivatives using reverse-phase high performance liquid chromatography. Analytical biochemistry, 1986. 154(1): p. 345-352.

106. Sullivan, M.L., J. Callis, and R.D. Vierstra, High performance liquid chromatography resolution of ubiquitin pathway enzymes from wheat germ. Plant physiology, 1990. 94(2): p. 710-716.

107. Loir, M., et al., Purification and characterization of ubiquitin from mammalian testis. FEBS letters, 1984. 169(2): p. 199-204.

108. Cox, K.A., et al., Conformer selection of protein ions by ion mobility in a triple quadrupole mass spectrometer. Journal of the American Society for Mass Spectrometry, 1994. 5(3): p. 127-136.

109. Loo, R.R.O. and R.D. Smith, Investigation of the gas-phase structure of electrosprayed proteins using ion-molecule reactions. Journal of the American Society for Mass Spectrometry, 1994. 5(4): p. 207-220.

110. Loo, J.A., et al., High-resolution tandem mass spectrometry of large biomolecules. Proceedings of the National Academy of Sciences, 1992. 89(1): p. 286-289. 
111. Badman, E.R., S. Myung, and D.E. Clemmer, Gas-phase separations of protein and peptide ion fragments generated by collision-induced dissociation in an ion trap. Analytical chemistry, 2002. 74(19): p. 4889-4894.

112. Myung, S., et al., Structural transitions of electrosprayed ubiquitin ions stored in an ion trap over 10 ms to 30 s. The Journal of Physical Chemistry A, 2002. 106(42): p. 99769982.

113. Carvalho, V.V., M.C. See Kit, and I.K. Webb, Ion mobility and gas-phase covalent labeling study of the structure and reactivity of gaseous ubiquitin ions electrosprayed from aqueous and denaturing solutions. Journal of the American Society for Mass Spectrometry, 2020. 31(5): p. 1037-1046.

114. Koeniger, S.L., S.I. Merenbloom, and D.E. Clemmer, Evidence for many resolvable structures within conformation types of electrosprayed ubiquitin ions. The Journal of Physical Chemistry B, 2006. 110(13): p. 7017-7021.

115. Gantman, T., et al., Conformers of ubiquitin 6+ for different charge distributions: Atomistic structures and ion mobility cross sections. The Journal of Physical Chemistry B, 2019. 123(30): p. 6401-6409.

116. Tai, H.-C. and E.M. Schuman, Ubiquitin, the proteasome and protein degradation in neuronal function and dysfunction. Nature Reviews Neuroscience, 2008. 9(11): p. 826-838.

117. Hochstrasser, M., Origin and function of ubiquitin-like proteins. Nature, 2009. 458(7237): p. $422-429$.

118. Pickart, C.M., Mechanisms underlying ubiquitination. Annual review of biochemistry, 2001. 70.

119. Cao, J. and Q. Yan, Histone ubiquitination and deubiquitination in transcription, DNA damage response, and cancer. Frontiers in oncology, 2012. 2: p. 26.

120. Komander, D., The emerging complexity of protein ubiquitination. Biochemical Society Transactions, 2009. 37(5): p. 937-953.

121. Shi, H.L. and D.E. Clemmer, Evidence for Two New Solution States of Ubiquitin by IMSMS Analysis. Journal of Physical Chemistry B, 2014. 118(13): p. 3498-3506.

122. Vijaykumar, S., C.E. Bugg, and W.J. Cook, Structure of Ubiquitin Refined at 1.8 a Resolution. Journal of Molecular Biology, 1987. 194(3): p. 531-544.

123. Schneider, D.M., M.J. Dellwo, and A.J.J.B. Wand, Fast internal main-chain dynamics of human ubiquitin. 1992. 31(14): p. 3645-3652.

124. Brutscher, B., R. Brüschweiler, and R.R.J.B. Ernst, Backbone dynamics and structural characterization of the partially folded A state of ubiquitin by $1 \mathrm{H}, 13 \mathrm{C}$, and $15 \mathrm{~N}$ nuclear magnetic resonance spectroscopy. 1997. 36(42): p. 13043-13053.

125. Wand, A.J., et al., Internal dynamics of human ubiquitin revealed by $13 C$-relaxation studies of randomly fractionally labeled protein, in Techniques in Protein Chemistry. 1997, Elsevier. p. 715-725. 
126. Vijay-Kumar, S., C.E. Bugg, and W.J. Cook, Structure of ubiquitin refined at 1.8Åresolution. Journal of Molecular Biology, 1987. 194(3): p. 531-544.

127. Vijay-Kumar, S., et al., Comparison of the three-dimensional structures of human, yeast, and oat ubiquitin. 1987. 262(13): p. 6396-6399.

128. Badman, E.R., C.S. Hoaglund-Hyzer, and D.E.J.J.o.t.A.S.f.M.S. Clemmer, Dissociation of different conformations of ubiquitin ions. 2002. 13(6): p. 719-723.

129. Kony, D.B., P.H. Hünenberger, and W.F. Van Gunsteren, Molecular dynamics simulations of the native and partially folded states of ubiquitin: Influence of methanol cosolvent, $p H$, and temperature on the protein structure and dynamics. Protein science, 2007. 16(6): p. 1101-1118.

130. Shi, H. and D.E. Clemmer, Evidence for Two New Solution States of Ubiquitin by IMS-MS Analysis. The Journal of Physical Chemistry B, 2014. 118(13): p. 3498-3506.

131. Shi, H., et al., Conformation types of ubiquitin [M+8H] 8+ ions from water: methanol solutions: evidence for the $N$ and A states in aqueous solution. The Journal of Physical Chemistry B, 2012. 116(10): p. 3344-3352.

132. Koeniger, S.L. and D.E. Clemmer, Resolution and structural transitions of elongated states of ubiquitin. Journal of the American Society for Mass Spectrometry, 2007. 18(2): p. 322331.

133. Fernández Peralbo, M.A., The Role of Microwaves in Omics Disciplines. 2013.

134. Patterson, S.D. and R. Aebersold, Mass spectrometric approaches for the identification of gel-separated proteins. Electrophoresis, 1995. 16(1): p. 1791-1814.

135. Mann, M., P. Højrup, and P. Roepstorff, Use of mass spectrometric molecular weight information to identify proteins in sequence databases. Biological mass spectrometry, 1993. 22(6): p. 338-345.

136. Yates, J.R., et al., Peptide mass maps: a highly informative approach to protein identification. Analytical biochemistry, 1993. 214(2): p. 397-408.

137. Eng, J.K., A.L. McCormack, and J.R. Yates, An approach to correlate tandem mass spectral data of peptides with amino acid sequences in a protein database. Journal of the american society for mass spectrometry, 1994. 5(11): p. 976-989.

138. Hunt, D.F., et al., Protein sequencing by tandem mass spectrometry. Proceedings of the National Academy of Sciences, 1986. 83(17): p. 6233-6237.

139. Mann, M. and M. Wilm, Error-tolerant identification of peptides in sequence databases by peptide sequence tags. Analytical chemistry, 1994. 66(24): p. 4390-4399.

140. Simpson, R.J., et al., Proteomic analysis of the human colon carcinoma cell line (LIM 1215): development of a membrane protein database. ELECTROPHORESIS: An International Journal, 2000. 21(9): p. 1707-1732.

141. Reid, G.E. and S.A. McLuckey, 'Top down' protein characterization via tandem mass spectrometry. J Mass Spectrom, 2002. 37(7): p. 663-75. 
142. Kelleher, N.L., et al., Top down versus bottom up protein characterization by tandem highresolution mass spectrometry. Journal of the American Chemical Society, 1999. 121(4): p. 806-812.

143. Meng, F., et al., Informatics and multiplexing of intact protein identification in bacteria and the archaea. Nature biotechnology, 2001. 19(10): p. 952-957.

144. Sze, S.K., et al., Top-down mass spectrometry of a 29-kDa protein for characterization of any posttranslational modification to within one residue. Proceedings of the National Academy of Sciences, 2002. 99(4): p. 1774-1779.

145. Smith, L.M., et al., Proteoform: a single term describing protein complexity. Nature Methods, 2013. 10(3): p. 186-187.

146. Bu, J., et al., Enhanced Reactivity in Nucleophilic Acyl Substitution Ion/Ion Reactions Using Triazole-Ester Reagents. Journal of the American Society for Mass Spectrometry, 2017. 28(7): p. 1254-1261.

147. Sun, Y., et al., Protein Structural Studies by Traveling Wave Ion Mobility Spectrometry: A Critical Look at Electrospray Sources and Calibration Issues. 2016. 27(1): p. 31-40.

148. Ruotolo, B.T., et al., Ion mobility-mass spectrometry analysis of large protein complexes. 2008. 3(7): p. 1139.

149. Bush, M.F., et al., Collision Cross Sections of Proteins and Their Complexes: A Calibration Framework and Database for Gas-Phase Structural Biology. Analytical Chemistry, 2010. 82(22): p. 9557-9565.

150. Ruotolo, B.T., et al., Ion mobility-mass spectrometry analysis of large protein complexes. Nature protocols, 2008. 3(7): p. 1139-1152.

151. Gabelica, V., et al., Recommendations for reporting ion mobility mass spectrometry measurements. 2019.

152. Webb, I.K., L.J. Morrison, and J.J.I.J.o.M.S. Brown, Dueling electrospray implemented on a traveling-wave ion mobility/time-of-flight mass spectrometer: Towards a gas-phase workbench for structural biology. 2019. 444: p. 116177.

153. Cai, W., et al., MASH Suite Pro: A Comprehensive Software Tool for Top-Down Proteomics. Mol Cell Proteomics, 2016. 15(2): p. 703-14.

154. Horn, D.M., R.A. Zubarev, and F.W. McLafferty, Automated reduction and interpretation of. Journal of the American Society for Mass Spectrometry, 2000. 11(4): p. 320-332.

155. Donnelly, D.P., et al., Best practices and benchmarks for intact protein analysis for topdown mass spectrometry. Nature Methods, 2019. 16(7): p. 587-594.

156. Ogorzalek Loo, R.R. and R.D. Smith, Investigation of the Gas-Phase Structure of Electrosprayed Proteins Using Ion-Molecule Reactions. Journal of the American Society for Mass Spectrometry, 1994. 5(4): p. 207-220.

157. Wyttenbach, T. and M.T.J.T.j.o.p.c.B. Bowers, Structural stability from solution to the gas phase: native solution structure of ubiquitin survives analysis in a solvent-free ion mobility-mass spectrometry environment. 2011. 115(42): p. 12266-12275. 
158. Li, J., et al., Influence of solvent composition and capillary temperature on the conformations of electrosprayed ions: unfolding of compact ubiquitin conformers from pseudonative and denatured solutions11Dedicated to Professor Michael T. Bowers on the occasion of his 60th birthday. International Journal of Mass Spectrometry, 1999. 185-187: p. 37-47.

159. Floris, F., et al., Top-Down Deep Sequencing of Ubiquitin Using Two-Dimensional Mass Spectrometry. Analytical Chemistry, 2018. 90(12): p. 7302-7309.

160. Robinson, E.W., R.D. Leib, and E.R. Williams, The role of conformation on electron capture dissociation of ubiquitin. Journal of The American Society for Mass Spectrometry, 2006. 17(10): p. 1470-1479.

161. Zhou, S. and M. Hamburger, Effects of solvent composition on molecular ion response in electrospray mass spectrometry: Investigation of the ionization processes. 1995. 9(15): $\mathrm{p}$. 1516-1521.

162. Tang, L. and P.J.A.c. Kebarle, Dependence of ion intensity in electrospray mass spectrometry on the concentration of the analytes in the electrosprayed solution. 1993. 65(24): p. 3654-3668.

163. Sjöberg, P.J., et al., A method for determination of ion distribution within electrosprayed droplets. 2001. 73(1): p. 23-28.

164. Cech, N.B. and C.G.J.M.s.r. Enke, Practical implications of some recent studies in electrospray ionization fundamentals. 2001. 20(6): p. 362-387.

165. Wyttenbach, T. and M.T. Bowers, Structural stability from solution to the gas phase: native solution structure of ubiquitin survives analysis in a solvent-free ion mobility-mass spectrometry environment. J Phys Chem B, 2011. 115(42): p. 12266-75.

166. Konermann, L. and D.J. Douglas, Unfolding of proteins monitored by electrospray ionization mass spectrometry: a comparison of positive and negative ion modes. Journal of the American Society for Mass Spectrometry, 1998. 9(12): p. 1248-1254.

167. Shi, H., et al., Conformation Types of Ubiquitin [M+8H]8+ Ions from Water:Methanol Solutions: Evidence for the $N$ and A States in Aqueous Solution. The Journal of Physical Chemistry B, 2012. 116(10): p. 3344-3352.

168. Shi, H. and D.E. Clemmer, Evidence for two new solution states of ubiquitin by IMS-MS analysis. The journal of physical chemistry. B, 2014. 118(13): p. 3498-3506.

169. Loo, J.A., et al., Solvent-induced conformational changes of polypeptides probed by electrospray-ionization mass spectrometry. 1991. 5(3): p. 101-105.

170. May, J.C., et al., Conformational landscapes of ubiquitin, cytochrome c, and myoglobin: Uniform field ion mobility measurements in helium and nitrogen drift gas. International Journal of Mass Spectrometry, 2018. 427: p. 79-90.

171. Liu, F.C., S.R. Kirk, and C. Bleiholder, On the structural denaturation of biological analytes in trapped ion mobility spectrometry - mass spectrometry. Analyst, 2016. 141(12): p. $3722-3730$. 
172. Shi, H., et al., Solution Dependence of the Collisional Activation of Ubiquitin $[M+7 H] 7+$ Ions. Journal of the American Society for Mass Spectrometry, 2014. 25(12): p. 2000-2008.

173. Lenkinski, R.E., et al., Nuclear magnetic resonance studies of the denaturation of ubiquitin. 1977. 494(1): p. 126-130.

174. Wilkinson, K.D., A.N.J.A.o.b. Mayer, and biophysics, Alcohol-induced conformational changes of ubiquitin. 1986. 250(2): p. 390-399.

175. May, J.C., et al., Conformational Landscapes of Ubiquitin, Cytochrome c, and Myoglobin: Uniform Field Ion Mobility Measurements in Helium and Nitrogen Drift Gas. Int J Mass Spectrom, 2018. 427: p. 79-90.

176. Koeniger, S.L. and D.E.J.J.o.t.A.S.f.M.S. Clemmer, Resolution and structural transitions of elongated states of ubiquitin. 2007. 18(2): p. 322-331.

177. Foreman, D.J., McLuckey, Scott A, Recent developments in gas-phase ion/ion reactions for analytical mass spectrometry. 2019. 92(1): p. 252-266.

178. Lermyte, F., et al., Characterization of top-down ETD in a travelling-wave ion guide. Methods, 2015. 89: p. 22-29.

179. Bu, J., et al., Selective covalent chemistry via gas-phase ion/ion reactions: an exploration of the energy surfaces associated with $N$-hydroxysuccinimide ester reagents and primary amines and guanidine groups. 2016. 27(6): p. 1089-1098.

180. Morrison, L.J. and J.S. Brodbelt, Charge site assignment in native proteins by ultraviolet photodissociation (UVPD) mass spectrometry. Analyst, 2016. 141(1): p. 166-176.

181. Fraczkiewicz, R. and W. Braun, Exact and efficient analytical calculation of the accessible surface areas and their gradients for macromolecules. Journal of computational chemistry, 1998. 19(3): p. 319-333.

182. Mendoza, V.L. and R.W. Vachet, Protein Surface Mapping Using Diethylpyrocarbonate with Mass Spectrometric Detection. Analytical Chemistry, 2008. 80(8): p. 2895-2904.

183. Harding, M.M., D.H. Williams, and D.N. Woolfson, Characterization of a Partially Denatured State of a Protein by 2-Dimensional Nmr - Reduction of the Hydrophobic Interactions in Ubiquitin. Biochemistry, 1991. 30(12): p. 3120-3128.

184. Bakhtiari, M. and L. Konermann, Protein Ions Generated by Native Electrospray Ionization: Comparison of Gas Phase, Solution, and Crystal Structures. The Journal of Physical Chemistry B, 2019. 123(8): p. 1784-1796.

185. Bleiholder, C. and F.C. Liu, Structure Relaxation Approximation (SRA) for Elucidation of Protein Structures from Ion Mobility Measurements. The Journal of Physical Chemistry B, 2019. 123(13): p. 2756-2769.

186. Cox, M.J., A.L. Haas, and K.D. Wilkinson, Role of ubiquitin conformations in the specificity of protein degradation: iodinated derivatives with altered conformations and activities. Arch Biochem Biophys, 1986. 250(2): p. 400-9.

187. Pan, Y.Q. and M.S. Briggs, Hydrogen-Exchange in Native and Alcohol Forms of Ubiquitin. Biochemistry, 1992. 31(46): p. 11405-11412. 
188. Stockman, B.J., A. Euvrard, and T.A. Scahill, Heteronuclear three-dimensional NMR spectroscopy of a partially denatured protein: the A-state of human ubiquitin. J Biomol NMR, 1993. 3(3): p. 285-96. 


\section{PUBLICATIONS}

[1] Carvalho, V. V., See Kit, M. C., \& Webb, I. K. (2020). Ion mobility and gas-phase covalent labeling study of the structure and reactivity of gaseous ubiquitin ions electrosprayed from aqueous and denaturing solutions. Journal of the American Society for Mass Spectrometry, 31(5), 10371046.

[2] Kit, M. C. S., Carvalho, V. V., Vilseck, J. Z., \& Webb, I. K. (2021). Gas-phase ion/ion

chemistry for structurally sensitive probes of gaseous protein ion structure: Electrostatic and electrostatic to covalent cross-linking. International Journal of Mass Spectrometry, 463, 116549. 